\title{
LINGÜÍSTICA Y NOMBRES DE LENGUAS EN EL DRAE. CRÍTICA Y PROPUESTAS
}

Francisco Rodríguez Adrados

$R A E$

\begin{abstract}
RESUMEN
El presente artículo propone renovar, mejorar y ampliar las definiciones de los nombres de lenguas que aparecen en el DRAE, que actualmente presentan notables carencias e inconsistencias.
\end{abstract}

Palabras clave: Lexicografía, DRAE, nombres de lenguas.

ABSTRACT

In this paper, the autor tries to renew, improve and expand the definitions of languages names contained in the DRAE. In the current edition, this dictionary presents significant lacks and inconsistencies.

Key Words: Lexicography, DRAE, languages names.

\section{INTRODUCCIÓN}

Se me ocurre sugerir la mejora de las definiciones lingüísticas y los nombres de lenguas que figuran en el $D R A E$, añadiendo otras muchas lenguas que allí faltan. Llevo años insistiendo sobre el tema, ahora pongo mis propuestas al día. No oculto que están sometidas, desde hace largo tiempo, al estudio de la Academia, pero que salgan al aire, que todos puedan verlas, me parece sano.

Propuse una parte de esto en el Congreso de Noviembre de 2002 de la RAE y las Academias Americanas en Puerto Rico: hubo comentarios favorables pero no se pasó de ahí. Luego publiqué un artículo en Corcillum. Estudios de traducción, lingüistica y filología dedicados a Valentín García Yebra (F. R. Adrados 2006). Finalmente, en octubre de 2009, he presentado otra versión. Han pasado ocho años.

Doy aquí una nueva versión más al día, creo que tengo derecho a que esto se haga público, independientemente de la decisión que tome la Academia. Una cosa son las decisiones, sometidas a diversas consideraciones, y otra el planteamiento teórico. Doy las gracias por su ayuda a D. Juan Antonio Álvarez-Pedrosa y D. Juan Carlos Moreno Cabrera. 
Intento que, al menos, el tema se conozca, porque todo esto está tratado en el DRAE, en mi opinión, que he hecho pública muchas veces, en forma muy mejorable. Con muchísimas lagunas y con definiciones erróneas o insuficientes. Para que el lector pueda juzgar, a cada propuesta añado la indicación de lo que dice o no dice el DRAE.

Para empezar, habría, en mi opinión, que mejorar en el DRAE algunas definiciones generales. He aquí mi propuesta.

- Primero, en relación con «lengua»:

1. En términos generales, se dice del resultado de la capacidad de los hombres de comunicarse entre sí por vía oral, y secundariamente escrita, mediante sistemas de fonemas y signos conocidos por emisores y receptores.

2. En términos concretos se dice de cada uno de los sistemas de comunicación oral, y secundariamente escrita, que son propios de un grupo humano. Es susceptible de englobar subconjuntos, llamados dialectos y variantes, propios de subgrupos de hablantes («los dialectos de la lengua griega»). Las lenguas pueden sufrir evolución, alteraciones y desaparición y generar, andando el tiempo, lenguas diferentes. Hay también, otras veces, la oposición lengua/dialecto, véase a continuación. Cuando se habla de una lengua determinada («la lengua griega»), la referencia es a la lengua y al conjunto de sus dialectos y variedades.

- Segundo, en relación con «dialecto»:

Se llama así a un sistema de comunicación oral que, dentro de una lengua determinada, introduce variantes sistemáticas, propias de un marco social, geográfico, científico, estilístico, etc., propio. La diferencia entre lengua y dialecto es sociolinguística: dialecto se dice de la variante de una lengua en boca de un número de hablantes reducido y que, en general, no tiene un status político, cultural y territorial reconocido y amplio. Históricamente, un dialecto puede, cuando se dan esas condiciones, pasar a ser llamado lengua. Así, el castellano fue primero un dialecto, es hoy una lengua.

- Tercero, sobre «variedad lingüística»:

Es cualquier realización de una lengua o dialecto en que se encuentran diferencias respecto al uso más común, pero menos profundas que en el caso de los dialectos. Por ejemplo, el andaluz o el canario son variedades del español que, a su vez, tienen subvariedades. 
- Cuarto, sobre «normalización» o «estandardización»:

Versión unificada, creada artificialmente en interés de nuevas entidades políticas, reales o simplemente buscadas, de antiguos grupos de dialectos, principalmente orales. Así, por ejemplo, el catalán unificado de Antoni Alcover y Pompeu Fabra; el vasco «batúa», creado sobre la base del guipuzcuano y el labortano por L. Michelena y otros; el macedonio estándar, creado a partir de dialectos eslavos sudoccidentales; etcétera.

- Quinto, sobre «familia lingüística»:

Se llama así a un conjunto de lenguas procedentes de una, que es su antepasado común: conocido directamente o bien por reconstrucción lograda mediante la comparación de las lenguas descendientes.

- Sexto:

Habría que definir términos como «Lingüística Estructural», «Sociolingüística», «Psicolingüística», «Lingüística Comparada», «Gramática», «Gramática Estructural», «Gramática Generativa», «speranto».

En lo que sigue, a mi propia definición añado, cuando es necesario, observaciones sobre su relación con la del DRAE o sobre su no existencia en este.

2. CRITERIOS A SEGUIR EN LA DEFINICIÓN DE LAS LENGUAS Y DIALECTOS.

CRÍticas AL DRAE

Cosas que se echan de menos en el DRAE:

1. ¿Lengua? ¿Dialecto? ¿Variedad? Hay que decidir en cada caso. Y evitar decir «gallego, lengua de los gallegos», «irlandés, lengua de los irlandeses», «osco, lengua osca», etc. Y faltan en el DRAE muchísimas lenguas.

Y como tanto en el uso adjetival como en el nominal hay coincidencia formal, a veces, entre el uso lingüístico y el étnico, sería preferible que el primero llevara la marca «Ling.»

2. Indicar territorio (a veces no se hace o es cambiante según las fechas): falta en definiciones del celta, finlandés, hetita, eslavo, albanés, etc. ¿Es lengua viva, extinta? No se dice, muchas veces. Si es posible, dar número aproximado de hablantes o, en todo 
caso, decir si la lengua es minoritaria (como el irlandés en Irlanda) o incluso desaparecida, extinta (el córnico, el prusiano, muchas lenguas amerindias y austronesias) o admite diferencias cronológicas (el griego).

A continuación, doy el número aproximado de hablantes, procedente de Moreno Cabrera 1990, sin duda atrasado, conviene revisarlo (se ha hecho en lo posible).

Doy un ejemplo de la evolución territorial: el vasco, implantado en Aquitania junto al mar, rodeado por los celtas, estuvo desde la antigüedad romana implantado en España, con fronteras a veces más amplias que las actuales. En la actualidad se habla, en España, en el País Vasco y parte de Navarra, y en Francia, en parte de los distritos de Bayona y Olorón. Esto habría que decirlo.

Debe hablarse de las sucesivas patrias del gótico y los godos, de lenguas y dialectos diversos.

Es importante saber si se trata de una lengua literaria o solo oral. Explicar detalles. Un mismo glotónomo puede tener varios significados: aragonés es en la Edad Media una lengua románica hablada en Aragón, hoy reducida a dialectos con pocos hablantes, la «fabla»; otra acepción es: actualmente, variedad del español hablada en Aragón. Un glotónimo puede aplicarse a una lengua en su conjunto, incluidos sus dialectos, también a la lengua unificada o estandardizada o bien, a dialectos o variedades de la misma (así el vasco, el gallego, el catalán). Todo esto habría que decirlo.

También es importante introducir en las definiciones, en varios casos, el carácter de ciertas lenguas como «lengua común de...», que convive con otras (por ej., así estaba en la anterior definición de «español» en el DRAE, que hice yo, luego se suprimió incomprensiblemente). Solo por ser lengua común se ha hecho oficial para todos. Son «lenguas comunes», por ejemplo, a más del español en España y muchas naciones, el Latín en el Imperio Romano (fue lengua de la antigua Roma y, posteriormente, lengua común del imperio, lo que no excluye la existencia de otras lenguas), el francés. Varias de ellas son, además, lenguas oficiales de una nación. Más en detalle, habría que precisar:

3. Familia lingüística, subfamilia, fecha. A veces no se indica la familia (no se dice la familia del osco, el noruego, el celta, el turco, el mongol, etc., ni que el danés es indoeuropeo germánico y, dentro de este, del grupo nórdico ni que el islandés es también nórdico, derivado del noruego, pero dentro del germánico). Ni se dice que el inglés es germánico occidental, con elementos de los anglos, jutos y sajones y, más tarde, del normando (¡que es una lengua románica!) y el danés. Es falso que diversas lenguas 
indias como el bengalí deriven del sánscrito, muerto desde muy pronto como lengua hablada. Aquellas otras lenguas derivan del indio medio, a saber, de lenguas prácritas emparentadas con el sánscrito pero más recientes. El bengalí se creó y se habla en la región de Bengala, hay que decir desde cuándo se conoce, cuándo se hizo lengua literaria. El etrusco no es una lengua desconocida y aislada, hoy se traduce y se piensa que es una lengua indoeuropea minorasiática, implantada en Italia hacia el siglo XII a. C. y testimoniada epigráficamente desde el vIII. El vasco: hay varias propuestas de parentesco lingüístico, ninguna demostrada, posiblemente procede de invasiones que llegaban a Europa de Asia en las edades neolítica y del cobre, invasiones en las que participaban, con los vascos, pueblos diversos: indoeuropeos, altaicos y otros. El vasco presenta huellas de contactos antiguos con lenguas celtas, secundarios con el latín, posteriores con el castellano.

4. Hacer referencia a los testimonios antiguos escritos. Carácter, fecha, alfabeto, etc. O, cuando se trata de lenguas no testimoniadas directamente, solo conocidas por el método comparativo, decirlo. Es importante esta indicación de testimonios para las lenguas germánicas y celtas, también para el griego, latín, sánscrito, etcétera.

\section{PROPUESTAS PARA MEJORAR Y SUPLEMENTAR LAS DEFINICIONES} DE LA LISTA DE GLOTÓNIMOS HISPÁNICOS EN EL DRAE (EXCLUYO LAS ACEPCIONES NO LINGÜÍSTICAS) ${ }^{1}$

Español, Ling. m. Lengua común de España y de muchas naciones de América, hablada también como propia en otras partes del mundo. En total, por unos 400 millones de personas ${ }^{2}$.

Gallego, Ling. m. Lengua románica derivada del gallego-portugués. Fue una importante lengua literaria desde el siglo XIII al XV y hoy se habla en Galicia y en zonas limítrofes de Asturias y León por unos tres millones de personas.

Gallego, -a. Adjetivo correspondiente a gallego.

Portugués, Ling. m. Lengua románica derivada del gallego-portugués, del que se independizó a partir del siglo XII como lengua del reino de Por-

\footnotetext{
1 Doy primero el uso nominal, luego el adjetival. Es lo normal, pero ya sé que no es el del $D R A E$, para mí es uno de sus mayores errores.

${ }^{2}$ Repito la antigua definición que hice yo y es muy superior a la introducida luego, no sé por quién.
} 
tugal. Es hablado por unos 140 millones de personas en Portugal y en zonas limítrofes de España, así como en el Brasil y en antiguas colonias portuguesas en África y Asia.

Castellano, Ling. m. 1. Dialecto derivado del latín en el confín de Castilla la Vieja con el País Vasco, testimoniado desde el siglo x y como lengua literaria y lengua del reino de Castilla, desde el XII, habiéndose difundido luego en el XIV por toda España como lengua común y oficial, y desde el XVI por América, luego por Guinea y otros lugares de África. 2. Sinónimo de «Español» como lengua común y oficial de España y otras naciones, usado especialmente cuando no se quiere distinguir de otras lenguas. 3 . También se usa cuando se quiere distinguirlo de variedades del español en España o fuera de ella ${ }^{3}$.

Castellano, -na, Ling. Adjetivo correspondiente a castellano como nombre, en sus diversas acepciones.

Murciano, Ling. m. Variedad de la lengua española que se habla en Murcia y en zonas limítrofes de otras provincias, también se llama «panocho».

Murciano, -na Ling. Adjetivo correspondiente a murciano.

Extremeño, Ling. m. Variedad de la lengua española que se habla en Extremadura.

Extremeño, -ña, Ling. Adjetivo correspondiente a extremeño.

Andaluz, Ling. m. Variedad de la lengua española hablada en Andalucía, que ofrece a su vez subvariedades (malagueño, granadino, etcétera).

Andaluz, -za, Ling. Adjetivo correspondiente a andaluz.

Canario, Ling. m. Variedad de la lengua española hablada en Canarias.

Canario, -a Ling. Adjetivo correspondiente a canario.

Catalán, Ling. m. Lengua románica que se habla, en España, en Cataluña, donde es lengua cooficial con el español, y fuera de ella, en Alguer (Cerdeña) y en el Rosellón (Francia) por unos 8 millones de personas. El término se aplica a la lengua en general, a su forma estandardizada y a sus dialectos. Era la lengua de la antigua Marca Hispánica, luego fue importante en el reino de Aragón y está documentada desde el siglo XII, siendo lengua literaria desde el XIII ${ }^{4}$.

Catalán, -na Ling. Adjetivo correspondiente a catalán.

Valenciano, Ling. m. Variedad del Catalán que se usa en gran parte del antiguo reino de Valencia y se siente allí comúnmente como lengua propia ${ }^{5}$.

Valenciano, -na, Ling. Adjetivo correspondiente a valenciano.

${ }^{3}$ Creo que esto mejora el DRAE y las «fichas aprobadas». Creo que es muy importante volver a decir «lengua común», insisto: está en la primera definición, que procede de mí; solo por ser lengua común se justifica que sea oficial.

${ }^{4}$ Quito el innecesario «vernácula».

${ }^{5}$ Respeto esta definición de D. Rafael Lapesa. 
Balear, Ling. m. Variedad o dialecto de la lengua catalana que se habla en las islas Baleares desde el siglo XIII. Tiene subvariedades como son el mallorquín, menorquín e ibicenco ${ }^{6}$.

Balear, Ling. Es el adjetivo, sin variante genérica, correspondiente a balear. Mallorquín, Ling. m. Subvariedad del mallorquín hablada en Mallorca.

Malloquín, -ina, Ling. Adjetivo correpondiente a mallorquín.

Menorquín, -ina, Ling. m. Subvariedad del balear hablada en Menorca.

Menorquín, -ina. Adjetivo correspondiente a menorquín.

Ibicenco, Ling. Subvariedad del balear hablada en Ibiza.

Ibicenco, -a. Adjetivo correspondiente a ibicenco.

Bable, Ling. m. Nombre que también reciben el asturiano y sus dialectos y variedades.

Asturleonés, Ling. m. Romance que en la Edad Media se hablaba en Asturias y en el antiguo reino de León y que dio origen, en la misma edad, al asturiano y el leonés.

Asturleonés, -sa, Ling. Es el adjetivo correspondiente a asturleonés.

Leonés, Ling. m. 1. Variedad del Asturleonés que se hablaba en León en la Edad Media. Se conservan dialectos leoneses residuales en ambos lados de la frontera hispano-portuguesa. 2. Variedad del castellano hablada en León ${ }^{7}$.

Leonés, -sa, Ling. Es el adjetivo correspondiente a leonés.

Asturiano, Ling. m. 1. Variedad del asturleonés medieval en Asturias, conservada en subvariedades locales llamadas bables. 2. Variedad del español hablada en Asturias ${ }^{8}$.

Navarroaragonés, Ling. m. Se dice del conjunto de dialectos romances medievales nacidos en Navarra y Aragón ${ }^{9}$.

Navarroaragonés, -sa, Ling. Es el adjetivo correspondiente al navarro-aragonés.

Aragonés, Ling. m. Subdialecto del Navarroaragonés hablado en la Edad Media en el reino de Aragón. Se conserva en el Pirineo aragonés como alto-aragonés, con dialectos minoritarios conocidos como «la fabla».

Fabla, Ling. f. Nombre que se da a los dialectos aragoneses conservados en el Pirineo aragonés ${ }^{10}$.

Aragonés, -sa, Ling. Es el adjetivo correspondiente a aragonés.

Vasco, Ling. m. (del nombre ide. *uarskunes 'los de las alturas', también vascogado y vascuence, también euskera o eusquera). Lengua no indoeuropea hablada en parte del País vasco-español y zonas limítrofes en

\footnotetext{
${ }^{6}$ Dejo en duda la diferencia variedad/dialecto e introduzco subvariedades, aquí y en los artículos que siguen.

7 Creo que mejora el DRAE.

8 Mejora el DRAE.

9 Preciso el DRAE con «medievales».

${ }^{10}$ Acepción que falta en DRAE.
} 
Navarra y en Francia (distritos de Bayona y Olorón) por cerca de un millón de personas. Es cooficial en la Autonomía del País Vasco y existen varias propuestas de parentesco lingüístico, ninguna demostrada; posiblemente procede de invasiones que llegaban a Europa de Asia en las edades neolítica y del cobre, invasiones en las que participaban pueblos diversos: indoeuropeos, altaicos y otros. El vasco presenta huellas de contactos antiguos con lenguas celtas, secundarios con el latín, posteriores con el castellano. Está testimoniado en topónimos, antropónimos, etc., primero en Aquitania, en fecha romana en el País vascoespañol y luego en textos escritos desde el siglo xvI. La denominación se aplica tanto al vasco en general como a su forma estandardizada (el batúa) y a sus varios dialectos.

\section{Amplío y preciso el DRAE, como sigue:}

Vasco, -a, Ling. Es el adjetivo correspondiente a vasco.

Vizcaíno, Ling. m. Uno de los dialectos ${ }^{11}$ vascos, hablado en Vizcaya.

Vizcaíno, -a, Ling. Es el adjetivo correspondiente a vizcaíno. Se dice «a la vizcaína» y «concordancia vizcaína» de los que hablan mal el español.

Guipuzcoano, Ling. m. Uno de los dialectos vascos, hablado en Guipúzcoa. Guipuzcoano, -a, Ling. m. Adjetivo correspondiente a guipuzcoano.

Panocho, Ling. m. Otro nombre del murciano, q. u.

Añado lenguas, dialectos y variedades:

El Labordano o Laburdano y el Suletino, dialectos vascos en Francia.

Castúo, Ling. Otro nombre del extremeño, q. u.

Aranés, Ling. Lengua románica no catalana hablada en el valle de Arán.

Judeoespañol, también llamado Ladino, Ling. m. Castellano arcaizante hablado por los judíos expulsados de España en 1492 y todavía vivo en Turquía, Grecia, Bulgaria, etcétera.

Sayagüés, Ling. m. Variedad del leonés, lengua de Sayago, en Zamora, usada a veces en parodia como lengua rústica de Salamanca en el siglo XVI.

Añado lenguas antiguas de Hispania que reflejan nuestro conocimiento actual y mejoran las definiciones del DRAE, cuando existen. A partir de aquí no doy los adjetivos correspondientes:

Lusitano, Ling., m. Lengua testimoniada en inscripciones de época romana con alfabeto latino en la antigua Lusitania. Se debate si se trata de un dialecto celta o si es una lengua indoeuropea independiente.

11 Llamo «dialectos» a este y los otros, como es usual. 
Ibérico, Ling. m. Lengua de los iberos, no indoeuropea pero no clasificada ni interpretada exactamente, pese a numerosas tentativas, testimoniada en el antiguo territorio de este pueblo a lo largo de la costa mediterránea de Francia y España hasta el territorio de Tartessos, entre el siglo v a. C. y nuestra era. Está escrita en un semisilabario de origen oriental (fenicio y griego), descifrado por Gómez Moreno en inscripciones y monedas, pero también está en un alfabeto derivado del griego y en el latino.

Tartesio, Ling. m. Lengua de los tartesios, a ella se atribuyen unas 70 inscripciones no descifradas, posiblemente de los siglos vi o v a. C., con una escritura propia silábico-alfabética, halladas en el Algarve portugués.

\section{INDOEUROPEO Y LENGUAS INDOEUROPEAS.}

\section{PROPUESTAS DE CORRECGIONES Y AÑADIDOS}

Indoeuropeo, Ling. m. Lengua del pueblo indoeuropeo, reconstruida en sus varios estratos temporales y dialectales por la comparación entre sí de las lenguas de él derivadas. Los indoeuropeos, entre los milenios quinto y primero a. C., en los períodos neolítico, del cobre y al final del hierro, se extendieron desde el centro de Asia primero por Anatolia (grupo anatolio, conocido después del desciframiento del hetita por Hrozny en 1917), luego por Europa, incluidas sus penínsulas e islas, y también por Asia (Anatolia, Irán, Afganistán, India, Sinkiang). Este último es el grupo del indoeuropeo tradicional, descubierto por Franz Bopp en 1824. Se crearon así las diferentes lenguas indoeuropeas, algunas de las cuales, como el español, portugués, francés y ruso, se extendieron luego por el mundo.

\section{En el $D R A E$ apenas hay nada. Preciso:}

\subsection{Lenguas anatolias}

Anatolias, Ling. f. Se denomina así a las lenguas de la oleada indoeuropea más antigua, que trajo lenguas arcaizantes conservadas en Anatolia, siendo el hetita la más importante de ellas, y sus derivaciones exteriores, sobre todo el etrusco.

Hetita o Hitita, Ling. m. Lengua indoeuropea anatolia de los hetitas o hititas, con capital en Hattusa (Bogazköy), que sus hablantes llamaban nesili. Se conserva en millares de tablillas conservadas en los archivos reales de Bogazköy y fechadas entre el siglo XVIII y el XIII a. C., también en las tablillas llamadas neohetitas del SE. de Anatolia y el N. de Siria (siglos XII-VIII a. C.). Se trata de un indoeuropeo muy arcaico, como el de las lenguas anatolias en general, carente aún de desarrollos propios del Indoeuropeo posterior y escrito en cuneiforme, tomado de los sumerios y de los pueblos semíticos que de ellos lo tomaron ${ }^{12}$.

12 El DRAE nada dice de estas lenguas. 
Palaíta, Ling. m. Lengua indoeuropea del grupo anatolio, cuyos textos más antiguos, en las inscripciones hetitas de Bogazköy, son del siglo XVI a. C. Se habló en la zona montañosa al norte del área hetita, próxima al Mar Negro $^{13}$.

Luvita, Ling. m. Lengua indoeuropea del grupo anatolio, transmitida por dos grupos de textos: los cuneiformes del segundo milenio a. C., procedentes de Bogazköy, y los jeroglíficos del primero, en la costa mediterránea, de la cultura llamada neohetita, al sur de la Península anatólica ${ }^{14}$.

Licio, Ling. m. Lengua indoeuropea de Licia, del grupo anatolio, documentada por una serie de textos del primer milenio a. C. escritos en un alfabeto derivado del griego ${ }^{15}$.

Cario, Ling. m. Lengua anatolia indoeuropea de Caria, conocida por textos del primer milenio a. C. escritos en un alfabeto derivado del griego ${ }^{16}$.

Lidio, Ling. m. Lengua indoeuropea del grupo anatolio, que se habló en Lidia y está documentada en textos, casi todos del siglo IV a. C., escritos en un alfabeto derivado del griego ${ }^{17}$.

Etrusco, Ling. m. Lengua hablada en Italia, en Etruria y en una vasta área de difusión en el centro y norte de la Península. Hoy se considera generalmente que es una lengua anatolia traída a Italia (y a Lemnos, donde una famosa estela presenta una lengua muy próxima) por los Pueblos del Mar y luego influida por el griego y dialectos itálicos. Del griego depende su alfabeto. El etrusco está testimoniado, principalmente, por un millar de inscripciones, hoy traducibles, de fechas que van del siglo VII al II a C., en que el etrusco fue absorbido por la lengua latina, sobre las que ejerció un importante influjo ${ }^{18}$.

Lemnio, Ling. m. Lengua de una estela de Lemnos del siglo vi a. C., muy próxima al etrusco.

Rético, Ling. m. Lengua testimoniada por unas 200 inscripciones halladas en el N. y NE. de Italia, de fechas entre los siglos v y II a. C., escritas en un alfabeto derivado del etrusco, con el que parece estar emparentado ${ }^{19}$.

\footnotetext{
13 El DRAE no lo menciona.

14 Sustituyo la definición tautológica del DRAE.

15 El DRAE solo da el territorio.

16 Nada de lengua en DRAE.

17 El DRAE solo da el territorio.

18 El DRAE dice cosas atrasadas.

19 No en el DRAE.
} 


\subsection{Lenguas célticas}

Celta, Ling. m. Lengua indoeuropea conocida en Europa central desde el siglo VIII a. C. (época de Hallstadt, luego en la de La Tène), posteriormente creó diversas lenguas y dialectos como el galo en Francia, Bélgica y el N. de Italia, el celtíbero en España, el goidélico o gaélico en las Islas Británicas, el britónico en el sur de Gran Bretaña y en la Bretaña francesa, el gálata en Asia Menor. Desplazados o sumergidos por germanos y romanos, los dialectos celtas han quedado reducidos hoy día a algunos restos en Irlanda (el irlandés), en Gran Bretaña (el gaélico, el manés, el córnico y el galés) y en Francia (el bretón). Las lenguas celtas son habladas hoy por unos dos millones y medio de personas ${ }^{20}$.

Galo, Ling. m. Antigua lengua celta testimoniada en Francia y regiones limítrofes por inscripciones en piedra y bronce en alfabeto griego y también latino a partir del siglo III a. C., sobre todo en el I a. C. y I d. C. Emparentado con el lepóntico, el celtíbero y el grupo del britónico.

Lepóntico, Ling. m. Lengua céltica testimoniada por inscripciones en el NO. de Italia y en Suiza, del IV a. C. al I d. C.

Celtíbero, Ling. m. Antigua lengua celta hablada en una zona de Castilla y el valle del Ebro y testimoniada por bronces (sobre todo los de Botorrita, de contenido legal), téseras de hospitalidad, monedas e inscripciones, escritas en alfabeto ibérico o latino, de edad romana, a partir del siglo I a. C. Está emparentado con el galo y el britónico, quizá con el lusitano $^{21}$.

Goidélico o Gaélico, Ling. m. Antigua lengua celta de la que hay datos antiguos y glosas desde el siglo Ix, procedentes de lenguas y dialectos hablados hoy, aunque en forma minoritaria, en Irlanda, la isla de Man, las Hébridas y el N. de Escocia.

Británico, Ling. m. Antigua lengua celta de la que proceden lenguas y dialectos hablados hoy, aunque en forma minoritaria, en el País de Gales, Cornualles y Bretaña.

Irlandés, Ling. m. Lengua céltica hablada, aunque minoritariamente, en Irlanda. Se conoce por inscripciones en la escritura llamada ogámica desde el siglo $v$ al viI d. C. y por palabras y luego textos literarios en alfabeto latino desde el siglo viII d. C. ${ }^{22}$.

Ogámico, -a Ling. Nombre dado al alfabeto usado en inscripciones celtas de las islas británicas desde el siglo IV d. C., en el cual a cada letra del alfabeto correspondía un número de rayas u otros trazos.

\footnotetext{
${ }^{20}$ En el DRAE hay cosas muy imprecisas.

21 Pone al día el DRAE.

22 Completa el DRAE, que es tautológico y falso.
} 
Bretón, Ling. m. Lengua céltica hablada minoritariamente en la Bretaña francesa y procedente principalmente del británico de Gran Bretaña. Se conoce desde el siglo vI d. C. Está escindido en varios dialectos. En total sus hablantes se acercan a un millón de personas.

Picto, Ling. m. Lengua celta que se habló en Escocia y que es conocida tan solo a través de nombres propios.

Galés, Ling. m. Lengua celta hablada, aunque minoritariamente, en el País de Gales y testimoniada en manuscritos desde el siglo XII d. C. ${ }^{23}$.

Manés, Ling. m. Lengua celta hablada, aunque minoritariamente, en la isla de Man.

Córnico, Ling. m. Lengua celta de la que tenemos escasa documentación medieval y que fue hablada minoritariamente hasta el siglo XVIII en la Península de Cornualles, hoy extinta.

Gálata, Ling. m. Lengua céltica hablada en Anatolia, en torno a Ankara, en la Antigüedad, de resultas de la invasión por parte de este pueblo celta en la segunda mitad del siglo III a. C.

\subsection{Griego y sus dialectos}

Griego, Ling. m. Lengua indoeuropea que penetró en Grecia desde el N. hacia el año 2000 a. C. Se habló, dividida en varios dialectos y subdialectos, en Grecia, donde está testimoniada desde el Micénico y la lengua homérica, en el II milenio a. C. (pero en Homero está retocada en el viII); luego en época arcaica y clásica, dividido en dialectos orientales y occidentales. Más tarde, bajo la forma de koiné o «griego común», se habló y escribió sucesivamente, con diversas variaciones, en los reinos helenísticos, el Imperio Romano Oriental, Bizancio y, con una reducción territorial, en la Grecia moderna. Hay que distinguir los distintos dialectos del griego antiguo (micénico, jonio, eolio, dorio) y las distintas variedades de la koiné antigua (en los reinos helenísticos y el imperio romano oriental) y bizantina. Hay, sobre todo, la dimotikí o «lengua popular», que es la base del griego moderno (oficial desde 1976) y la katharévusa o «lengua pura». El griego se ha escrito sucesivamente en un silabario, el micénico, y un alfabeto, este derivado del fenicio, desde el siglo IX a. C. y aceptado con generalidad en su variedad jónica desde fines del siglo $\mathrm{V}$ a. C. El griego ha sido y es el modelo de todas las lenguas cultas y científicas del mundo; y el alfabeto griego, de sus alfabetos. El griego moderno se habla hoy en Grecia, Chipre y en la diáspora, sobre todo en Estados Unidos y Australia, por unos 11 millones de personas.

Micénico, Ling. m. Dialecto griego de los micénicos, de escritura silábica, emparentado con los dialectos alfabéticos posteriores de Homero y de

23 Tautológico en el DRAE. 
los jonios y eolios, es decir, con el antiguo griego oriental. Es conocido por tablillas de arcilla cocida de los siglos XIV y XIII a. C., que fueron halladas en los archivos de los palacios micénicos y contienen textos documentales escritos en un silabario, llamado lineal B, que es una modificación del silabario minoico o lineal B. Fue descifrado en 1954 por M. Ventris ${ }^{24}$.

Jonio o Jónico, Ling. m. Dialecto griego antiguo, del grupo oriental, que llegó a Grecia desde el Norte hacia el año 2000 a. C. Era hablado desde el siglo IX a. C. o antes en el litoral de Asia Menor, en las islas Cícladas y en Ática, donde donde surgió la variedad llamada ático.

Aqueo, Ling. m. Se llama así al dialecto griego de Homero y la épica griega.

Ático, Ling. m. Variedad del dialecto jónico, surgida en Atenas y convertida desde el siglo v a. C. en el principal dialecto literario griego, a partir del cual se creó la koiné o lengua común griega.

Koiné, Ling. f. Denominación del griego común, es decir, la lengua griega común o unificada derivada del ático que, después de las conquistas de Alejandro, fue la lengua general del mundo griego, base también del griego bizantino y moderno. La koiné tuvo en la Antigüedad variantes populares y literarias, e igual en Bizancio y Grecia moderna; y de las primeras (la dimotikí o lengua popular) surgió en el siglo xx el griego de nuestros días, el que llamamos griego moderno. El término koiné se usa también para denominar otras «lenguas comunes».

Eolio, Ling. m. Era, en la Antigüedad, al lado del Jonio, el segundo gran grupo de dialectos del griego oriental, en la antigua Grecia.

Lesbio, Ling. m. Dialecto eolio de la isla de Lesbos, en la antigua Grecia.

Beocio, Ling. m. Dialecto eolio de Beocia, en la antigua Grecia.

Tesalio, Ling. m. Dialecto eolio de Tesalia, en la antigua Grecia.

Arcadio, Ling. m. Dialecto griego de Arcadia, próximo al chipriota y los dos emparentados con el jonio y el eolio, todo ello en la antigua Grecia.

Chipriota, Ling. m. Dialecto griego de Chipre, próximo al arcadio, ambos emparentados con el jonio y el eolio, todo ello en la antigua Grecia. Se escribe en un silabario propio.

Dorio, Ling. m. Era, en la Antigüedad, el principal dialecto del griego occidental, llegado a Grecia desde el Norte hacia el año 1000 a. C.

Corintio, Ling. m. Dialecto dorio de Corinto, en la antigua Grecia.

${ }^{24}$ No aparece como lengua en DRAE. 
Egineta, Ling. m. Dialecto dorio de Egina, en la antigua Grecia.

Megarense, Ling. m. Dialecto dorio de Mégara, en la antigua Grecia.

Cretense, Ling. m. Dialecto dorio de Creta, en la antigua Grecia.

Argivo, Ling. m. Dialecto dorio de Argos, en la antigua Grecia.

Eleo, Ling. m. Dialecto griego de Elea, del grupo del NO., emparentado con el dorio dentro del grupo del griego occidental, en la antigua Grecia.

Siracusano, Ling. m. Dialecto dorio de Siracusa, en la antigua Magna Grecia.

Délfico, Ling. m. Dialecto griego de Delfos, en la antigua Grecia ${ }^{25}$.

\subsection{Lenguas indoeuropeas de Italia y Suiza}

\section{Doy solo las más conocidas y no citadas antes o después:}

Latín, Ling. m. En el comienzo, un dialecto del grupo indoeuropeo conocido como latinofalisco, llegado a Italia desde el N. hacia el año 1000 a. C. El latín fue luego lengua del Lacio, de ahí su nombre, y de Roma dentro de él; más tarde fue lengua común y oficial del Imperio romano en torno al Mediterráneo. Sus testimonios más antiguos son del siglo VI a. C., se hizo lengua literaria en el siglo II a. C. y desapareció como lengua hablada común en el siglo v d. C. Pero sobrevivió como latín vulgar y en sus derivados romances, también como lengua de la Iglesia y de los doctos (latín eclesiástico, medieval, humanístico, latín científico usado hasta hoy).

Falisco, Ling. m. Un dialecto dentro del antiguo grupo indoeuropeo del latinofalisco, propio de la ciudad de Falerii. Fue absorbido pronto por el latín.

Equo, Ling. m. Lengua indoeuropea itálica, hablada por los equos, al N. del lago Fucino, absorbida luego por el latín. Está testimoniada epigráficamente.

Osco, Ling. m. Lengua del grupo indoeuropeo conocido como osco-umbro o también itálico, próximo al latín pero diferente. Como este, llegó a Italia atravesando los Alpes hacia el año 1000 a. C. El osco era hablado por las tribus samnitas de la Italia meridional y está testimoniado por numerosas inscripciones de entre los siglos IV y I a. C., siendo luego absorbido por el latín.

Umbro, Ling. m. Lengua del grupo indoeuropeo conocido como osco-umbro o también itálico, próximo al latín pero diferente. Como este, llegó

${ }_{25}$ Todos estos términos no son referidos a la lengua en el DRAE. 
a Italia atravesando los Alpes hacia el año 1000 a. C. El umbro era hablado en Umbría y está testimoniado sobre todo por las Tablas Iguvinas, de entre los siglos IV y I a. C. Fue luego absorbido por el latín.

Marrucino, Ling. m. Lengua indoeuropea itálica, hablada por los marrucinos, en la costa adriática central, absorbida luego por el latín. Está testimoniada epigráficamente.

Marso, Ling. m. Lengua indoeuropea itálica hablada por los Marsos cerca del lago Fucino, absorbida luego por el latín. Está testimoniada epigráficamente.

Sabino, Ling. m. Lengua indoeuropea itálica hablada por los sabinos, en la zona de Reate, se conoce por palabras transmitidas indirectamente. Fue absorbido luego por el latín.

Véneto, Ling. m. Lengua indoeuropea hablada en el extremo NE. de Italia. Está testimoniado por inscripciones en alfabeto etrusco, de entre los siglos VI y i a. C. Fue absorbido luego por el latín.

Volsco, Ling. Lengua indoeuropea itálica hablada por los volscos, al S. de Roma, y transmitidas por inscripciones de en torno al siglo III a. C. Fue absorbido luego por el latín.

Mesapio. Ling. m. Lengua indoeuropea hablada en la Apulia en los siglos anteriores a Cristo. Conocida epigráficamente, quizá esté relacionada con el ilirio. Fue absorbida por el latín.

Sículo, Ling. m. Lengua citada por autores griegos y latinos como hablada al sudoeste del Etna y que se considera indoeuropea, a juzgar por los vestigios que conocemos.

\subsection{Lenguas indoeuropeas de Europa: lenguas romances}

Subapartado de lenguas y dialectos romances, dejando fuera los de Hispania, ya vistos.

Corso, Ling. m. Lengua romance de Córcega, de rasgos lingüísticos muy diferentes de los dialectos italianos ${ }^{26}$.

Sardo, Ling. m. Lengua romance de Córcega, de rasgos más arcaicos, muchas veces, que el italiano y muy dialectizada ${ }^{27}$.

Italiano, Ling. m. Lengua común y oficial de Italia, que ha logrado este status gradualmente, desde su comienzo como dialecto toscano escrito en el

${ }^{26}$ En DRAE no hay acepción lingüística.

27 Retoco Sardo 6. 
siglo XIV. Antes, desde el siglo x, hay textos que anticipan ya el italiano. Es hablado por unos 65 millones de personas ${ }^{28}$.

Retorromance, Ling. m. Dialecto alpino del italiano, que comprende el ladino, el friulano y el romanche ${ }^{29}$.

Ladino, Ling. m. 1. Variedad del retorromance hablado en Italia y el Tirol. 2. Otro nombre del judeo-español ${ }^{30}$.

Friulano, Ling. m. Dialecto hablado en los Alpes centrales y en la región de Trento, del grupo del retorromance ${ }^{31}$.

Romanche, Ling. m. Dialecto del retorromance, hablado en Suiza ${ }^{32}$.

Piamontés, Ling. m. Dialecto italiano septentrional, hablado en el Piamonte ${ }^{33}$.

Lombardo, Ling. m. Dialecto italiano septentrional, hablado en Lombardía ${ }^{34}$.

Veneciano, Ling. m. Dialecto italiano septentrional, hablado en Venecia ${ }^{35}$.

Emiliano, también llamado Romañol, Ling. m. Dialecto italiano septentrional, hablado en la Emilia o Romaña ${ }^{36}$.

Toscano, Ling. m. Dialecto italiano central, de Toscana, del que ha nacido el italiano estándar ${ }^{37}$.

Romanesco, Ling. m. Dialecto de Roma, a medio camino entre el toscano y el napolitano y hoy casi desaparecido ${ }^{38}$.

Napolitano, Ling. m. Dialecto italiano meridional, centrado en la zona de Nápoles $^{39}$.

Calabrés, Ling. m. Dialecto italiano meridional, hablado en Calabria.

Siciliano, Ling. m. Dialecto italiano meridional, hablado en Sicilia ${ }^{40}$.

\footnotetext{
28 Amplío italiano 3.

29 Retoco retorrománico 1.

30 Retoco ladino 6 y 7 del DRAE.

31 Retoco friulano 3 del DRAE.

32 DRAE lo identifica con rético, en todo caso será con el retorromance.

${ }_{33}$ No aparece como lengua en DRAE.

${ }_{34}$ No aparece como lengua en DRAE.

35 Está en DRAE.

$36 \mathrm{Ni}$ lo uno ni lo otro en DRAE.

${ }_{37}$ No aparece como lengua en DRAE.

38 No aparece como lengua en DRAE.

39 Sí está en DRAE, Napolitano 3.

40 Sí en DRAE.
} 


\subsection{Lenguas y dialectos romances de Francia, con su difusión fuera de ella}

Dejo aparte lenguas de los troncos catalán, italiano, celta, germánico y vasco. No incluyo dialectos menos conocidos.

Francés, Ling. m. Lengua común y nacional de Francia y oficial o cooficial en Bélgica y en numerosas naciones de África, América y Oceanía. Procede del latín a través de la lengua de la Isla de Francia, es la más distinguida de las llamadas «lenguas oíl». Testimoniada desde el siglo IX y protegida por los reyes, fue declarada lengua oficial por Francisco I (ordenanza de Villers-Cotterêts, 1539) y tiene una gran supremacía frente a varios dialectos que siguen existiendo, como también hay variedades del francés en Canadá, Bélgica y entre los acadios de Luisiana. Lo hablan unos 72 millones de personas ${ }^{41}$.

Normando, Ling. m. Dialecto francés del grupo de las lenguas oíl, hablado en Normandía. Su variedad medieval influyó grandemente en el inglés ${ }^{42}$.

Gallo, Ling. m. Dialecto francés del grupo «oíl» hablado en Alta Bretaña ${ }^{43}$.

Picardo, Ling. m. Dialecto francés del grupo «oíl», hablado en Picardía ${ }^{44}$.

Valón, Ling. m. Dialecto francés del grupo «oíl», hablado por los valones de Bélgica y de la zona limítrofe francesa ${ }^{45}$.

Borgoñón Ling. m. Dialecto francés del grupo «oíl», hablado en Borgoña ${ }^{46}$

Gascón, Ling. m. Dialecto francés del grupo occitano, hablado en Gascoña, al O. del río Garona ${ }^{47}$.

Provenzal, también Francoprovenzal, Ling. m. Lengua principal de entre las occitanas, importante literariamente y por su influjo en otras lenguas desde el siglo XI, pero que ha decaído enormemente por una serie de circunstancias históricas. Todavía se habla residualmente y se trata de hacerla revivir literariamente ${ }^{48}$.

\subsection{Lengua romance en los Balcanes: el rumano}

Rumano, Ling. m. Lengua romance derivada de la ocupación de la Dacia por los romanos entre los años 106 y 221 d. C. Se habla en Rumanía,

\footnotetext{
${ }^{41}$ Amplío la definición de DRAE.

42 Amplío Normando 3.

${ }^{43}$ Falta en DRAE.

${ }^{44}$ Mejora Picardo 3.

45 Cf. Valón 3.

${ }^{46}$ DRAE: dice tan solo que es una variedad del francés antiguo.

${ }^{47}$ Sí en DRAE, más o menos.

48 Confuso en DRAE 2-4.
} 
Hungría y Ucrania por unos 20 millones de personas y está rodeada e influido por lenguas eslavas. Se escribió primero en el alfabeto eslavo, desde 1868 en el latino ${ }^{49}$.

\subsection{Lenguas y dialectos indoeuropeos del grupo germánico}

\section{Doy solo los más conocidos.}

Germánico, Ling. m. Lengua de una rama de los indoeuropeos que penetró en Europa hacia el año 1000 a. C. por el N. de los Cárpatos, y se dividió en tres subramas, del N., del E. y del O. El germánico y sus tres ramas son reconstruidos a partir de la comparación entre las diversas lenguas germánicas históricas, que son testimoniadas desde época precristiana por la escritura rúnica y por testimonios griegos y latinos. La totalidad del germánico se distingue del resto de indoeuropeo, entre otras cosas, por la llamada mutación consonántica por la que, por ejemplo, la $d$ se cambia en $t$ y la $g$ en $k^{50}$.

Runas, Ling. f. pl. Inscripciones escritas en lengua germánica y en alfabeto rúnico desde los siglos III y IV d. C. El alfabeto rúnico está basado en alfabetos latinos del N. de Italia, a su vez dependientes del griego ${ }^{51}$.

Escandinavo, Ling. m. Forma del germánico septentrional que permaneció viva hasta el siglo IX d. C. y de la cual salieron, entre otras lenguas, el danés, el noruego y el sueco ${ }^{52}$.

Danés, Ling. m. El danés es la lengua de Dinamarca, nacida de la rama oriental del germánico septentrional. Influyó grandemente en el noruego y fue regularizado en el siglo XVIII. Es hablado por unos 5 millones de personas $^{53}$.

Noruego, Ling. m. Lengua de Noruega, procedente de la rama occidental del germánico septentrional y con variante más o menos influidas por el danés. De su forma antigua surgieron el islandés y el feroés. Hoy es hablado por unos 5 millones de personas ${ }^{54}$.

Islandés, Ling. m. Lengua de Islandia, nacida del antiguo noruego en los siglos IX/X d. C. En su forma antigua, muy arcaizante, creó la gran épica nórdica del Edda, reflejada en obras de los siglos XIII y XIV principalmente. Es hablado por unas 150.000 personas ${ }^{55}$.

\footnotetext{
49 DRAE: Rumano, lengua de los rumanos.

50 Amplío el DRAE.

51 DRAE: definición muy parcial.

${ }^{52}$ No hay acepción lingüística en DRAE.

53 DRAE: lengua que se habla en Dinamarca.

${ }^{54}$ DRAE: lengua de Noruega.

55 Amplío la definición del DRAE.
} 
Feroés, Ling. m. Lengua de las islas Feroe, nacida del antiguo noruego ${ }^{56}$.

Sueco, Ling. m. Lengua de Suecia, procedente de la rama oriental del germánico septentrional. Es hablado por unos 10 millones de personas ${ }^{57}$.

Gótico, Ling. m. Lengua germánica oriental de los godos que, partiendo probablemente de la isla de Gotland, descendieron a mediados del siglo III d. C. al Mar Negro y tuvieron relaciones pacíficas y guerreras con Bizancio. Se cristianizaron adscribiéndose a la secta arriana y hacia el $350 \mathrm{~d}$. C. el obispo arriano Ulfilas tradujo la Biblia griega al gótico. De este libro, conservado parcialmente, proviene la mayor parte de nuestro conocimiento de esta lengua. En cambio, de los ostrogodos, que fundaron un reino en el norte de Italia, y los visigodos, que lo hicieron en el sur de la Galia y en Hispania, han quedado pocos restos lingüísticos ${ }^{58}$.

Burgundio, Ling. m. Lengua germánica oriental del pueblo burgundio, apenas conocida ${ }^{59}$.

Vándalo, Ling. m. Lengua germánica oriental del pueblo vándalo, apenas conocida ${ }^{60}$.

Alemán, Ling. m. Conjunto de lenguas germánicas entre el Báltico, el Mar del Norte, la frontera del francés, los Alpes y la frontera de las lenguas eslavas. Se distinguen, de un lado, el bajo alemán propiamente dicho (conjunto de dialectos en el O. y N. de Alemania) y lenguas emparentadas, entre ellas el frisón, el sajón, el neerlandés, el holandés, y el flamenco; y el alto alemán o alemán estándar, en el centro y sur de Alemania, que presenta una segunda mutación consonántica (la $t$ germánica se hizo $z$, la $k$ se hizo $h$ ). Nacido en la zona de Franconia y Turingia y popularizado como lengua culta por ser la de la Biblia de Lutero, solo en el siglo XIX se hizo lengua estándar y común de Alemania, Austria y Suiza, y se habla también en el N. de Italia y Bélgica, entre otras zonas. A su lado siguen viviendo varios dialectos. El alemán lo hablan unos 110 millones de personas ${ }^{61}$.

Frisón, Ling. m. Dialecto del grupo del bajo alemán en Frisia, aunque una parte de sus hablantes emigró a Inglaterra en el siglo v d. C. y contribuyó a formar el inglés. Hoy lo hablan en Frisia unas 500.000 personas ${ }^{62}$.

Anglo, Ling. m. Lengua germánica del Schleswig que, emigrada a Inglaterra en el siglo v d. C., contribuyó a formar el inglés ${ }^{63}$.

\footnotetext{
56 No aparece en el DRAE.

${ }_{57}$ Amplía la definición del DRAE.

58 Amplía la definición del DRAE.

${ }^{59}$ No figura en el DRAE.

${ }^{60}$ No hay acepción ling. en el DRAE.

61 Cf. DRAE: 3. Idioma alemán.

${ }^{62} D R A E$ : lengua germánica hablada por los frisones.

${ }_{63}$ No aparece en este sentido en el DRAE.
} 
Sajón, Ling. m. Lengua germánica del N. de Alemania. Una parte de sus hablantes emigró a Inglaterra en el siglo v d. C. y contribuyó a formar el inglés ${ }^{64}$.

Franco, Ling. m. Lengua de los francos que atravesaron el Rin y penetraron en la Galia, para convertirse al Cristianismo ya en el siglo v d. C. El franco desapareció luego, absorbido por las lenguas románicas ${ }^{65}$.

Longobardo, Ling. m. Lengua de los longobardos, pueblo germánico que, bajando desde el Elba, ocupó Lombardía en el siglo vi d. C., para ser conquistado por los francos y desaparecer su lengua ${ }^{66}$.

Yídico o Yidis, Ling. m. Lengua germánica hablada en el valle del Rin, que se convirtió en lengua judía en Europa, los Estados Unidos e Israel, aceptando gran número de hebraísmos. Sus hablantes se calculan en unos 4 millones ${ }^{67}$.

Fráncico Lorenés, Ling. m. Dialecto germánico que se habla en Lorena ${ }^{68}$.

Alsaciano, Ling. m. Dialecto germánico hablado en Alsacia ${ }^{69}$.

Luxemburgués, Ling. m. Dialecto germánico que es lengua oficial en Luxemburgo. Lo hablan unas 500.000 personas $^{70}$.

Neerlandés, Ling. m. Lengua germánica del grupo del bajo alemán que es oficial de Holanda y Bélgica. Lo hablan unos 25 millones de personas ${ }^{71}$.

Holandés, Ling. m. Variante dialectal del neerlandés hablada en Holanda ${ }^{72}$.

Flamenco, Ling. m. Variante del neerlandés hablada en Bélgica y en la zona contigua de Francia ${ }^{73}$.

Africaans o Africano, Ling. m. Variante del neerlandés, desarrollada en Sudáfrica por los colonos holandeses del siglo XVI: hablado hoy por unos 9 millones de personas ${ }^{74}$.

Inglés, Ling. m. Lengua germánica oficial en Inglaterra. Procede de invasiones desde el siglo $\mathrm{V}$ d. C., de pueblos germánicos que llevaban lenguas del bajo alemán (yutos, anglos, frisones, sajones). Recibió influjos del latín,

\footnotetext{
64 Completa Sajón 3 del DRAE.

65 Completa Franco 10 en el DRAE.

${ }^{66}$ Completa Longobardo 4 en el DRAE.

${ }_{67}$ No figura en el DRAE.

68 No figura en el DRAE.

69 Está en el DRAE.

${ }^{70}$ No figura en el DRAE.

71 Está en el DRAE.

72 No en el DRAE.

73 DRAE, Flamenco 7: idioma flamenco.

74 Está en el DRAE.
} 
el danés y el normando y desde el siglo Ix fue lengua literaria. Luego se ha convertido en lengua oficial de países del mundo como Estados Unidos y Canadá y en segunda lengua de muchísimos millones de personas. Se calcula que sus hablantes son unos 450 millones de personas. Es la lengua más difundida del globo ${ }^{75}$.

\subsection{Lenguas indoeuropeas del grupo baltoeslavo}

\section{Solo las más conocidas.}

Baltoeslavo, Ling. m. Dialecto indoeuropeo que se reconstruye como fuente del báltico y el eslavo, si es que no son, más bien, dos lenguas muy emparentadas. Sus portadores penetraron, quizá, en la Europa oriental en los siglos I a. C. /I d. C. ${ }^{76}$.

Báltico, Ling. m. Rama del indoeuropeo, derivada según algunos de un anterior baltoeslavo, que penetró en Europa hacia los siglos I. a. C. / I. d. C. El grupo báltico estuvo situado, en un momento, al oeste de la línea RigaMoscú-Kiev, luego, empujado por el eslavo ruso, mantuvo su dominio en torno al mar Báltico ${ }^{77}$.

Prusiano, Ling. m. Lengua báltica de la Prusia oriental, desaparecida desde el siglo XVIII ${ }^{78}$.

Lituano, Ling. m. Lengua báltica de Lituania, escrita tan solo desde el siglo XVI. Es hablada por unos tres millones de personas en Lituania y por unos cientos de miles en Estados Unidos ${ }^{79}$.

Letón, Ling. m. Lengua báltica de Letonia, escrita solo desde el siglo XVI. Es hablada por un millón y medio de personas en Letonia ${ }^{80}$.

Eslavo, Ling. Rama del indoeuropeo, derivada según algunos de un anterior baltoeslavo, que penetró en Europa hacia el comienzo de nuestra era y se estableció al este del germánico, bordeando el rumano y el norte del griego y otras lenguas y dejando núcleos o huellas dentro de ellas. Es hablado por unos 270 millones de personas en Europa. Se extendió con el ruso por Asia Central y Siberia; y varias lenguas eslavas se hablan también en Estados Unidos. Existen, a nivel mundial, unos 300 millones de hablantes de lenguas eslavas. Hay tres subgrupos del eslavo: el meridional, el oriental y el occidental ${ }^{81}$.

\footnotetext{
${ }^{75}$ DRAE: lengua inglesa.

76 Mejora DRAE.

77 Mejora DRAE.

${ }^{78}$ No figura en el DRAE.

${ }^{79}$ Mejora Lituano 3 del DRAE.

${ }^{80}$ Mejora Letón 4 del DRAE.

${ }^{81}$ Mejora Eslavo 3, 4 del DRAE.
} 
Búlgaro, Ling. m. Lengua eslava, llevada en el siglo vi d. C. por los eslavos y los búlgaros (pueblo turco que luego se eslavizó) a Grecia y Bulgaria, donde finalmente se asentó. El búlgaro antiguo, también llamado eslavo eclesiástico, fue la lengua eslava que, en un reino unificado desde 681 d. C., primero se escribió en alfabetos derivados del griego (el cirílico y el glagolítico) y, a partir de traducciones de textos cristianos en griego, se convirtió en lengua literaria. Esos alfabetos, así como otros derivados de ellos, fueron usados por las demás lenguas eslavas, salvo las occidentales, que usaron y usan el alfabeto latino. Hablan el búlgaro unos 9 millones de personas $^{82}$.

Macedonio, Ling. m. Lengua eslava meridional estandardizada recientemente, hablada en la república eslava de Macedonia por unos dos millones y medio de personas. No debe confundirse con el macedonio antiguo ${ }^{83}$.

Serbocroata, Ling. m. Lengua eslava meridional, que es oficial en Serbia y Croacia con los nombres, respectivamente, de serbio y croata, lenguas que presentan pequeñas diferencias entre sí, pero se escriben en alfabeto eslavo la primera y latino la segunda. En total lo hablan unos 17 millones de personas ${ }^{84}$.

Esloveno, Ling. m. Lengua eslava meridional, que se habla en Eslovenia por unos dos millones de personas ${ }^{85}$.

Ruso, Ling. m. Lengua eslava oriental hablada en Rusia europea y Siberia, también tiene hablantes en los territorios de las antiguas naciones soviéticas de Europa y Asia. Es hablado por unos 150 millones de personas ${ }^{86}$.

Bielorruso, Ling. m. Llamado también ruso blanco, es una lengua eslava oriental hablada en Bielorrusia por unos 7 millones de personas ${ }^{87}$.

Ruteno, Ling. m. Lengua eslava oriental hablada en Ucrania, también en Eslovaquia y $\operatorname{Serbia}^{88}$.

Checo, Ling. m. Lengua eslava occidental oficial en Chequia, hablada por unos 12 millones de personas ${ }^{89}$.

Eslovaco, Ling. m. Lengua eslava occidental oficial de Eslovaquia, hablada por unos cuatro millones de personas ${ }^{90}$.

\footnotetext{
${ }^{82}$ Cf. Búlgaro 3 en el DRAE («lengua búlgara»).

${ }^{83}$ No figura como lengua en el DRAE.

${ }^{84}$ No figura en el DRAE.

${ }^{85}$ Completa Esloveno 3 del DRAE.

86 En DRAE: Ruso 3 «lengua rusa».

${ }^{87}$ Completa Bielorruso 3 del DRAE.

88 Cf. Ruteno 4 en el DRAE.

89 Completa Checo 4 en el DRAE.

90 «Lengua de los eslovacos» en el DRAE.
} 
Casubo, Ling. m. Lengua eslava oriental hablada en Polonia, minoritaria ${ }^{91}$.

Sorabo, Ling. m. Lengua eslava oriental hablada en Alemania oriental, minoritaria ${ }^{92}$.

Ucraniano, Ling. m. Lengua eslava oriental hablada en Ucrania, por unos 50 millones de personas ${ }^{93}$.

Polaco, Ling. m. Lengua eslava occidental, oficial de Polonia. Lo hablan unos 40 millones de personas $^{94}$.

\subsection{Lenguas indoeuropeas del grupo indo-iranio}

\section{Solo doy las más conocidas.}

Indoiranio, Ling. m. Lengua indoeuropea reconstruida a partir de las lenguas de ella derivadas. Se piensa que penetró hacia el Sur desde la llanura de Asia Central a través de un corredor desde el norte del Mar Caspio, a fines del tercer milenio a. C. Luego se escindió en dos grandes lenguas, iranio e indio, que a su vez produjeron lenguas y dialectos transmitidos por escrito a partir de un momento ${ }^{95}$.

Iranio, Ling. m. Lengua escindida del indoiranio y que luego produjo, ya dentro del Irán, las diferentes lenguas iranias y algunas de Asia central ${ }^{96}$.

Indio, Ling. m. Lengua escindida del indoiranio y que luego produjo, ya dentro de la India, las diferentes lenguas indias. Se divide en antiguo (védico y sánscrito), medio (los diversos prácritos) y moderno ${ }^{97}$.

Persa, Ling. m. 1. Nombre que se da al persa antiguo, lengua irania conocida por las grandes inscripciones de los reyes persas del imperio Aqueménida, de Darío I a Artajerjes III (siglos VI-IV a. C.). La lengua está próxima al avéstico y se escribe en cuneiforme con varias innovaciones. 2. Lengua irania moderna, también llamada farsi, hablada sobre todo en el centro del país, la hablan unos 30 millones de personas ${ }^{98}$.

Farsi, Ling. m. Nombre del persa moderno, hablado en el centro del Irán ${ }^{99}$.

${ }^{91}$ No figura en el DRAE.

${ }_{92}$ No figura en el DRAE.

${ }_{93}$ Completa Ucraniano 3 en el DRAE.

${ }_{94}$ Completa Polaco 4 en el DRAE.

${ }_{95}$ Completa el DRAE.

${ }^{96}$ Completa Iranio 3 en el DRAE.

${ }_{97}$ No figura en el DRAE.

${ }_{98}$ Completa Persa 5 del DRAE.

${ }^{99}$ No figura en el DRAE. 
Avéstico, Ling. m. Antigua lengua irania en la que está escrito el Avesta, el libro sagrado de la religión de Zoroastro, en un alfabeto especialmente creado. En realidad el Avesta es un conjunto de elementos de diversas edades, la primera parte, los llamados Gathas, son posiblemente de la misma edad que el Veda indio; otras, de la de Zoroastro (siglo VI a. C.), pero reelaboradas más tarde; otras aún, son posteriores ${ }^{100}$.

Pelví, también pehleví, Ling. m. Lengua del iranio medio, testimoniada sobre todo en textos de la religión zoroástrica de época sasánida, siglos del III al VII d. C. ${ }^{101}$.

Parto, Ling. m. Lengua irania de los partos, tribu procedente del Asia Central que estableció un reino independiente en el Irán en el siglo III a. C. y combatió con seleúcidas (la monarquía helenística de Siria) y romanos. Se conocen textos desde el año 88 a. C. y de la primera época sasánida ${ }^{102}$.

Sasánida, Ling. m. Lengua irania que fue la lengua oficial del imperio sasánida $(226-652 \text { d. C. })^{103}$.

Curdo, Ling. m. Lengua irania de los curdos, pueblo establecido en una zona que hoy día es en parte de Turquía, en otra de Iraq y en una tercera de Siria, también en diversos lugares del Cáucaso. La hablan unos 15 millones de personas ${ }^{104}$.

Osético, Ling. m. Lengua irania de Osetia y Georgia, lo hablan en torno a medio millón de personas ${ }^{105}$.

Chugní, Ling. m. Lengua irania del Tayikistán ${ }^{106}$.

Yazgulami, Ling. m. Lengua irania del Tayikistán ${ }^{107}$.

Pasto, Ling. m. Lengua irania del Afganistán y el Pakistán. Lo hablan unos 20 millones de personas ${ }^{108}$.

Baluchi, Ling. m. Lengua irania del Baluchistán, Irán y Pakistán. Lo hablan unos tres millones y medio de personas ${ }^{109}$.

Tayiki, Ling. m. Lengua irania del Tayikistán, hablada por unos dos millones y medio de personas ${ }^{110}$.

\footnotetext{
100 Completa Avéstico 2 del DRAE.

101 Retoca el artículo del DRAE.

102 No hay acepción lingüística en el DRAE.

103 No hay acepción lingüística en el DRAE.

104 No hay acepción lingüística en el DRAE.

105 No figura en el DRAE.

106 No figura en el DRAE.

107 No figura en el DRAE.

108 No figura en el DRAE.

${ }^{109}$ No figura en el DRAE.

${ }^{110}$ No figura en el DRAE.
} 
Védico, Ling. m. Lengua india antigua, considerada sagrada, de los himnos recogidos por los cuatro Vedas, que se cree compuestos, los más antiguos, en torno al año 1000 a. C. Fueron transmitidos primero por tradición oral, luego en el silabario devanagari ${ }^{111}$.

Sánscrito, Ling. m. Lengua india antigua, derivada del védico, usada en los Brahmanas, Upanisads y demás comentarios del Veda y luego, como «lengua perfecta», que eso significa la palabra, usada como lengua escrita de las religiones (incluido el Budismo) y de la literatura y pensamiento de la India en general. En el siglo III a. C. el sánscrito ya no existía como lengua vulgar. Se escribía habitualmente en devanagari ${ }^{112}$.

Prácritos, Ling. m. plu. Se llama así colectivamente a una serie de dialectos del indio medio, derivados del sánscrito, que se hablaban y escribían desde el siglo III a. C. o incluso antes ${ }^{113}$.

Hindi, Ling. m. Principal lengua india moderna, lengua oficial de la India junto con el inglés, hablada por unos 230 millones de personas, sobre todo en Uttar Pradesh y Madhya Pradesh. Deriva del indio medio indoeuropeo y se escribe en un silabario derivado del devanagari ${ }^{114}$.

Urdú, Ling. m. Nombre que recibe el hindi en Pakistán, donde es una variante del mismo y se escribe en alfabeto árabe. Lo hablan unos 85 millones de personas $^{115}$.

Magadhi, Ling. m. Uno de los prácritos del indio medio, hablado en esta región ${ }^{116}$.

Guyarati, Ling. m. Uno de los prácritos del indio medio y su derivado actual, con una gran literatura desde el siglo XV d. C. y hablado hoy por unos 35 millones de personas ${ }^{117}$.

Marati, Ling. m. Lengua india indoeuropea hablada en el estado de Maharashtra, en el que está Bombay, por unos 35 millones de hablantes ${ }^{118}$.

Cachemir, Ling. m. Lengua india indoeuropea hablada en Cachemira por unos tres millones de personas y escrita ya en devanagari ya en alfabeto árabe ${ }^{119}$.

Penyabí, Ling. m. Lengua india indoeuropea hablada en el Penyab, en India y Pakistán, por unos 80 millones de personas ${ }^{120}$.

\footnotetext{
111 No figura en el DRAE.

112 Mejora Sánscrito, del DRAE.

113 Mejora Prácrito en el DRAE.

114 Mejora Hindi en el DRAE.

115 Mejora Urdú en el DRAE.

116 No figura en el DRAE.

117 No figura en el DRAE.

118 Cf. el DRAE.

119 No figura en el DRAE.

${ }^{120}$ No figura en el DRAE.
} 
Nepalí, Lin. m. Lengua india indoeuropea hablada en Nepal, Assam, Sikkim y Bhután por unos tres millones de personas ${ }^{121}$.

Sindí, Ling. m. Lengua india hablada en Pakistán por unos 7 millones de personas $^{122}$.

Pali, Ling. m. Uno de los prácritos del indio medio, en el que se escribió la más antigua tradición budista y que se mantiene hoy en Sri Lanka (Ceilán) como lengua sagrada ${ }^{123}$.

Cingalés, Ling. m. Lengua oficial de Sri Lanka (Ceilán), derivada del indio medio y traída desde el N. de la India por los colonos budistas. Tiene un silabario muy diferente del devanagari y lo hablan unos 11 millones de personas $^{124}$.

Maldivo, Ling. Lengua de las islas Maldivas, derivada del cingalés ${ }^{125}$.

Romaní, también gitano o caló, Ling. m. Lengua de la comunidad gitana en muchos lugares del mundo, derivada del indio medio. Sus hablantes se calculan en unos 6 millones ${ }^{126}$.

Bengalí, Ling. m. Lengua india indoeuropea derivada del indio medio y hablada en Bengala (Bangla Desh) e India por unos 160 millones de hablantes. Posee una literatura muy importante ${ }^{127}$.

Oriya, Ling. m. Lengua india indoeuropea hablada en el estado de Orissa por unos 25 millones de personas ${ }^{128}$.

Asamés, Ling. m. Lengua india hablada en el estado de Assam por unos 20 millones de personas ${ }^{129}$.

\subsection{Lenguas de otros grupos indoeuropeos}

Ilirio, Ling. m. Lengua indoeuropea del Illiricum romano, en la orilla oriental del Adriático, muy pobremente documentada, quizá emparentada con el mesapio y con el albanés ${ }^{130}$.

\footnotetext{
${ }^{121}$ No figura en el DRAE.

122 No figura en el DRAE.

123 Mejora el DRAE.

124 No hay acepción lingüística en el DRAE.

125 No hay acepción lingüística en el DRAE.

${ }^{126}$ En el DRAE los otros dos términos remiten a caló, que se atribuye a los gitanos españoles.

${ }^{127}$ Amplía y mejora Bengalí 4 en el DRAE.

${ }_{128}$ No figura en el DRAE.

129 No figura en el DRAE.

${ }^{130}$ No tiene acepción lingüística en el DRAE.
} 
Albanés, Ling. m. Lengua indoeuropea de Albania, quizá descendiente del antiguo ilirio. Lo hablan unos 5 millones de personas ${ }^{131}$.

Macedonio, Ling. m. Lengua indoeuropea de los antiguos macedonios, conocida solo por nombres propios y referencias, considerada por unos como un dialecto griego, por otros como uno próximo al tracio. No debe confundirse con el macedonio eslavo ${ }^{132}$.

Tracio, Ling. m. Lengua indoeuropea hoy extinta, hablada desde al menos el siglo VII a. C. en buena parte de los Balcanes hasta el Mar Egeo, emparentado quizá con el dacio y el geta ${ }^{133}$.

Dacio, Ling. m. Antigua lengua indoeuropea de los dacios, en la actual Rumanía, posiblemente emparentada con el tracio ${ }^{134}$.

Geta, Ling. m. Antigua lengua indoeuropea de los getas, asentados en el siglo IV d. C. en el bajo Danubio, seguramente emparentada con el tracio ${ }^{135}$.

Frigio, Ling. m. Antigua lengua indoeuropea de los frigios, en la costa mediterránea y el interior de Asia Menor. Los frigios posiblemente llegaron con los tracios, griegos y armenios, hacia el año 2000 a. C. y han dejado inscripciones, desde el siglo VII a. C, en un alfabeto tomado del griego ${ }^{136}$.

Armenio, Ling. m. Lengua indoeuropea del grupo del griego, el tracio y el frigio, que hacia el 2000 a. C. llegó a Grecia, mientras que la rama armenia y frigia atravesó los Dardanelos y ocupó la Península anatolia. Los armenios se instalaron en la zona del lago Van y el monte Ararat. Están testimoniados desde fecha antigua pero su alfabeto, fundado en el griego, no se creó hasta comienzos del siglo v d. C. Mantuvieron siempre el Cristianismo. El armenio está vivo en la república de Armenia, en Turquía y Siria y también en la diáspora en Francia y Estados Unidos sobre todo. Lo hablan unos 6 millones de personas ${ }^{137}$.

Tocario, Ling. $\mathrm{m}$. El tocario es la lengua de un pueblo indoeuropeo que emigró en dirección al Este, en vez de al Oeste como los demás. Se estableció en el Xinquián, donde está testimoniado por noticias indirectas en los siglos anteriores a Cristo. Se han encontrado textos tocarios de los siglos IX y X d. C., que son versiones de literatura india budista, en dos dialectos: el A (oriental, en Turfán) y el B (occidental, en Kucha). Hoy los tocarios han desaparecido, la región se llama Sinkiang, está ocupada por el pueblo turco de los vigures, que son musulmanes. Forma parte de China ${ }^{138}$.

\footnotetext{
131 En el DRAE, Albanés: lengua albanesa.

${ }^{132}$ El DRAE no ofrece acepción lingüística.

${ }^{133}$ El DRAE no ofrece acepción lingüística.

134 El DRAE no ofrece acepción lingüítica.

135 El DRAE no ofrece acepción lingüística.

${ }^{136}$ En el DRAE no hay acepción lingüística.

137 En el DRAE, Armenio 5: lengua armenia.

138 En el DRAE, idioma indoeuropeo del Turquestán chino.
} 


\section{Lenguas no indoeuropeas de Europa, Asia y ÁfricA (SOLO LAS MÁS CONOCIDAS)}

\section{Como prólogo puede citarse:}

Nostrático, Ling. m. Nombre dado por los lingüistas a una antigua lengua de la que habrían nacido el Indoeuropeo, el Semítico, el Finougrio, el Uralo-altaico y otras lenguas más, según los diversos lingüistas ${ }^{139}$.

\subsection{En Europa (además de las ya indicadas en España)}

Sicano, Ling. m. Lengua antigua hablada en Sicilia, al parecer no indoeuropea ${ }^{140}$.

Elimo, Ling. m. Lengua antigua del extremo nordoccidental de Sicilia, que algunos consideran emparentada con el elamita del Irán ${ }^{141}$.

Minoico, Ling. m. Lengua de la antigua Creta, recogida en la llamada escritura Lineal A, de entre 1800 a 1450 a. C., no descifrada todavía. El disco de Festos, de hacia 1700 a. C., contiene una escritura jeroglífica tampoco descifrada, pero no se cree que escriba el minoico del Lineal $\mathrm{A}^{142}$.

Uraloaltaico, Ling. m. Grupo lingüístico que engloba el del urálico y el del altaico, ambos de procedencia asiática y de los cuales las lenguas más conocidas son, del primero, el finés y el húngaro, que entraron en Europa, y del segundo, el turco ${ }^{143}$.

Urálico, Ling., m. Grupo de lenguas cuya patria original estuvo entre el Volga y el Obi en el cuarto milenio a. C. y del cual salió el ugrofinés, de este el húngaro, el finés y otras lenguas ${ }^{144}$.

Ugrofinés, Ling. m. Rama del urálico, de la que nacieron el húngaro y el finés, entre otras lenguas ${ }^{145}$.

Húngaro, Ling. m. Lengua urálica, del grupo del ugrofinés, que hacia el año 2000 a. C. penetró en Europa. En el 896 entró en Hungría, donde esta lengua ha continuado viva hasta ahora, también en la parte occidental de Rumanía. Lo hablan unos 16 millones de personas ${ }^{146}$.

\footnotetext{
139 En el DRAE no se encuentra.

${ }^{140}$ En el DRAE, sin acepción lingüística.

141 En el DRAE no figura.

${ }^{142}$ En el DRAE no hay acepción lingüística.

143 Retoco el DRAE.

144 Retoca urálico, en el DRAE

145 Rehago el DRAE.

146 Mejoro el DRAE.
} 
Finés, Ling. m. Lengua de la familia ugrofinesa, que se estableció en Finlandia. Lo hablan cerca de 6 millones de personas ${ }^{147}$.

Lapón, Ling. m. Lengua de la familia ugrofinesa, también llamada sami, establecida en el norte de la Península escandinava y de Rusia ${ }^{148}$.

Carelio, Ling. m., lengua de la familia ugrofinesa, establecida en Carelia. No llegan a 200.000 hablantes $^{149}$.

Sami, Ling. m. Véase Lapón.

Estonio, Ling. m. Lengua de la familia ugrofinesa, establecida en el litoral oriental del Mar Báltico. Son cerca de un millón de hablantes ${ }^{150}$.

Samoyedo, Ling. m. Lengua, con varios dialectos, de la familia ugrofinesa, establecida en el norte de Rusia ${ }^{151}$.

\subsection{Varias lenguas de Asia, dificiles de organizar en familias}

Solo las más conocidas.

Urartu, Ling. m. Lengua hablada en la Antigüedad en la zona del monte Ararat y el lago Van, en la actual Turquía, que los urartu defendieron de los asirios hasta el siglo viI a. C. En las fortalezas de los urartu quedan inscripciones en escritura cuneiforme ${ }^{152}$.

Elamita, Ling. m. Lengua hablada en el NO. del Irán, en las regiones del Luristán y Khozistán, desde el tercer milenio a. C. hasta el final del imperio persa $^{153}$.

Caucásico, Ling. m. Se da este nombre a las numerosas lenguas del Cáucaso, en la Antigüedad y modernamente. Hay el grupo del Norte y el del Sur, pero no es posible establecer entre ellos relaciones genealógicas, ni tampoco, muchas veces, entre las lenguas de cada uno.

Kartvélico o Kartúlico, Ling. m. Grupo de lenguas habladas al sur del Cáucaso, que se cree originadas en el v milenio. Entre ellas está el georgiano ${ }^{154}$.

\footnotetext{
${ }^{147}$ En el DRAE: idioma finés.

${ }^{148}$ En el DRAE: lengua hablada por los lapones.

149 En el DRAE no figura.

${ }^{150}$ En el DRAE: lengua finesa hablada en este país.

151 Retoco el DRAE.

${ }^{152}$ En el $D R A E$ no figura.

${ }^{153}$ En el DRAE no figura.

${ }^{154}$ En el DRAE no figura ni con $k$ - ni con $c$-.
} 
Georgiano, Ling. m. Lengua no indoeuropea del Cáucaso, testimoniada desde el siglo v a. C., hoy en día lengua oficial de Georgia. Cuenta con unos 4 millones de hablantes ${ }^{155}$.

Hático, Ling. m. Lengua de la población de la meseta anatolia antes de la llegada de los hetitas, a los que por error se ha dado su nombre ${ }^{156}$.

Hurrita, Ling. m. Lengua de un reino situado al N. de Siria y en partes de los actuales Irak y Turquía. Está testimoniado desde el tercer milenio a. C. ${ }^{157}$.

Mitanni, Ling. m. Lengua no indoeuropea del poderoso reino Mitanni, fundado por los hurritas y situado al N. de Siria, desde el tercer milenio a. C. ${ }^{158}$.

Kasita, Ling. m., Lengua de los casitas, que habitaron en los montes Zagros hasta la época de Alejandro ${ }^{159}$.

Sumerio, Ling. m. Es la gran lengua de cultura mesopotámica, desde el cuarto milenio a. C. hasta cerca de la era cristiana. Era escrito, desde el tercer milenio, usando primero ideogramas, luego el silabario cuneiforme más numerales y determinantes ${ }^{160}$.

Dravídico, Ling. m. Se denominan así las lenguas preindoeuropeas de la India, habladas por los drávidas, habitantes preindoeuropeos en la India, que han tenido y tienen gran vivacidad en la parte meridional de la India. Son unos 140 millones de hablantes ${ }^{161}$.

Tamil, Ling. m. La principal lengua dravídica en el sur de la India, estados de Tamil Nadu y limítrofes, y de Ceilán, poseedora de una importante literatura influida por la de las lenguas indoeuropeas de la India. Lo hablan más de 60 millones de personas ${ }^{162}$.

Malabar, Ling. m. Una lengua dravídica de la India, emparentada con el tamil. Lo hablan 33 millones de personas en la costa SO. de la India' ${ }^{163}$.

Canarés, Ling. m. Una lengua dravídica de la India, hablada en la Costa SO. de la India, estado de Karnataka, por unos 30 millones de personas ${ }^{164}$.

Telugú, Ling. m. Lengua dravídica hablada en Andhra Pradesh, en India, por unos 74 millones de personas ${ }^{165}$.

\footnotetext{
${ }^{155}$ En el DRAE no tiene acepción lingüística.

${ }^{156}$ En el DRAE no figura.

${ }^{157}$ En el DRAE no figura.

${ }^{158}$ En el DRAE no figura.

159 En el DRAE no figura, ni con $k$ - ni con $c$-.

${ }^{160}$ En el DRAE: lengua sumeria.

161 Mejoro Dravídico. 3 del DRAE.

${ }^{162}$ Mejoro Tamil. 4 del DRAE.

163 En el DRAE: lengua de los malabares.

${ }^{164}$ En el DRAE no figura.

165 En el DRAE no figura.
} 
Aleutoesquimal, Ling. m. Gran familia lingüística que se extiende por la zona norte de Canadá, Estados Unidos, Groenlandia, Rusia europea y Siberia ${ }^{166}$.

Ainú, Ling. m. Lengua de origen desconocido y hablada, aunque muy escasamente, en las islas de Hokkaido, las Kuriles y Sakhalín ${ }^{167}$.

\subsection{Familia uraloaltaica}

Altaico, Ling. m. Gran grupo de familias de lenguas, emparentado con el Urálico, que se extiende desde Rusia y Asia central a China y descendió también más al Sur, por obra de invasiones de mongoles, turcos y tártaros ${ }^{168}$.

Azerí, Ling. m. Lengua turca hablada por unos 10 millones de personas en Azerbaiyán, Kazakistán, Uzbekistán, Turkmenistán y Kirguizistán ${ }^{169}$.

Uigur, Ling. m. Lengua turca hablada en la región de Sinkiang, en China, y en algunos otros lugares de Asia Central, son unos 6 millones de hablantes ${ }^{170}$.

Turco, Ling, m. Gran grupo de lenguas del grupo llamado túrcico, dentro del altaico, muy difundido en Asia central y, desde que los turcos atravesaron el Eúfrates en el siglo XI d. C., también en Anatolia y luego en los Balcanes. Por antonomasia se llama simplemente turco al de la Turquía actual, hablado por unos 77 millones de personas ${ }^{171}$.

Turcomano, Ling. m. Lengua turca hablada en el Turkmenistán y también en Irán, Irak, Afganistán y Uzbekistán. La hablan unos 3 millones de personas $^{172}$.

Kazako, Ling. m., Lengua turca hablada sobre todo en el Kazakistán, también en China y Mongolia por unos 7 millones de personas ${ }^{173}$.

Kirguís o Quirguíz, Ling. m. Lengua turca hablada sobre todo en el Kirguizistán, por unos dos millones de personas ${ }^{174}$.

Tártaro, Ling. m. Lengua altaica hablada en Crimea y en algunos estados de Asia central. Son unos 9 millones de hablantes ${ }^{175}$.

\footnotetext{
${ }^{166}$ En el DRAE no figura.

${ }_{167}$ En el DRAE no figura.

168 Retoca el DRAE.

169 Retoca el DRAE.

${ }^{170}$ En el DRAE no figura.

171 No presenta acepción lingüística en el DRAE.

${ }^{172}$ En el DRAE no presenta acepción lingüística.

${ }^{173}$ En el DRAE no presenta acepción lingüística.

${ }_{174}$ Solo Quirguís figura como lengua en DRAE.

${ }^{175}$ En el DRAE hay Tártaro 3: lengua hablada en esta región.
} 
Uzbeko, Ling., m. Lengua altaica hablada en el Uzbekistán, también en Afganistán, por unos 13 millones de hablantes ${ }^{176}$.

Mongol, Ling. m. Lengua altaica hablada en Mongolia y China por unos 4 millones de personas ${ }^{177}$.

Japonés, Ling. m. Lengua del Japón, testimoniada desde el siglo III d. C. y hablada hoy por unos 140 millones de personas. Se escribió primero con la escritura china, luego con sistemas ya ideográficos ya silábicos, hoy frecuentemente con el alfabeto latino. Muchos lingüistas consideran el japonés, junto con el coreano, como una lengua uraloaltaica ${ }^{178}$.

Coreano, Ling. m. Lengua de Corea, escrita primero, desde el siglo I a. C., en escritura china, luego en un alfabeto inventado en el siglo XV. Presenta rasgos gramaticales semejantes a los del japonés y, como este, es considerado con frecuencia como perteneciente a la familia uraloaltaica. Lo hablan unos 78 millones de personas ${ }^{179}$.

\subsection{Lenguas de varias familias en Asia y África}

Aleuta, Ling. m. Lengua próxima al esquimal hablada en las islas Aleutianas ${ }^{180}$.

Esquimal, Ling. m. Familia de lenguas dentro del grupo aleutoesquimal, en el norte de Canadá, Groenlandia y Eurasia ${ }^{181}$.

Afroasiático, Ling. m. Familia de lenguas formada principalmente por los grupos bereber, chádico, cusita, egipcio y semita ${ }^{182}$.

Bereber, Ling. m. Familia de lenguas hablada desde la Antigüedad en el interior del norte de África y en zonas contiguas. Sus hablantes se calculan en unos 12 millones ${ }^{183}$.

Guanche, Ling. m. Lengua extinta de las Islas Canarias, del grupo bereber ${ }^{184}$. Rifeño, Ling. m. Dialecto bereber del Rif ${ }^{185}$.

Tuareg, Ling. m. Lengua de los tuareg, pueblo nómada del Sahara, de la familia bereber ${ }^{186}$.

\footnotetext{
176 En el DRAE no hay acepción lingüística.

177 En el DRAE: lengua de los mongoles.

178 En el DRAE: idioma del Japón.

${ }^{179}$ En el DRAE: lengua propia de los coreanos.

${ }^{180}$ No figura en el DRAE, pero sí esquimal-aleutiano.

181 Retoco Esquimal 4. del DRAE.

182 En el DRAE no hay acepción lingüística.

183 Cf. DRAE Bereber 4.

${ }^{184}$ En el DRAE: lengua que hablaron los guanches.

185 En el DRAE, sin acepción lingüística.

186 En el DRAE, sin acepción lingüística.
} 
Chádico, Ling. m. Familia de lenguas en torno al lago Chad ${ }^{187}$.

Hausa, Ling. m. Lengua de Nigeria, Tanganica, Benín, Camerún, etc., del grupo chádico. La hablan unos 20 millones de personas ${ }^{188}$.

Kusita, Ling. m. Familia de lenguas del grupo Chádico, hablado en Etiopía, Somalía y Africa central y sudoriental ${ }^{189}$.

Somalí, Ling. m. Lengua de la familia cusita, hablado en Somalía, Etiopía, Kenia, Yemen, Djibuti. La hablan unos 6 millones de personas ${ }^{190}$.

Egipcio, Ling. m. Lengua del antiguo Egipto, testimoniada por escrito desde el tercer milenio a. C. al siglo III d. C., primero en la escritura jeroglífica, que contiene ideogramas provistos a veces de indicaciones fónicas. Desde el siglo VII a. C. hay una variante llamada egipcio demótico o popular ${ }^{191}$.

Copto, Ling. m. Lengua derivada del antiguo egipcio (su etimología es «egipcio») pero escrita en un alfabeto derivado del griego, que se habló y escribió del siglo III al VII d. C. y fue luego utilizada por la iglesia copta, estando prácticamente extinto desde el siglo XVI ${ }^{192}$.

Semita, Ling. m. Gran familia de lenguas, en Asia y África, traída también a Occidente por las invasiones árabes y la diáspora judía y, últimamente, árabe. Tiene alfabetos derivados, en última instancia, de escrituras del Sinaí y Fenicia, de donde derivó, también, el alfabeto griego. Se distinguen grupos de lenguas semíticas septentrionales, centrales y meridionales ${ }^{193}$.

Eblaíta, Ling. m. Es la lengua semítica septentrional de la ciudad de Ebla, cuyas ruinas han sido desenterradas recientemente en el N. de Siria (siglo XXIV a. C.) La escritura es cuneiforme, derivada del sumerio ${ }^{194}$.

Amorreo, Ling. m. Una serie de variantes lingüísticas de una lengua semítica recogidas en tablillas halladas en el N. de Siria, pertenecientes a los milenios III y II a. C. ${ }^{195}$.

Ugarítico, Ling. m. Se llama así a la lengua semítica septentrional que se descubrió en 1929 en Ras Shamra, antigua Ugarit, en la costa de Siria del Norte. A ella pertenece el primer prototipo del alfabeto, del que deriva el griego ${ }^{196}$.

Acadio, Ling. m. Lengua semítica oriental de Acad, de los milenios III/II a. C., escrita en una escritura cuneiforme de tipo sumerio ${ }^{197}$.

\footnotetext{
${ }^{187}$ En el DRAE: perteneciente o relativo a este grupo de lenguas.

188 En el DRAE, sin acepción lingüística.

189 El DRAE dice: cusita «grupo de lenguas habladas en África oriental».

190 En el DRAE: lengua somalí.

191 DRAE: idioma egipcio.

192 En el DRAE: idioma antiguo de los egipcios que se conserva en la liturgia.

193 En el DRAE no en sentido lingüístico, solo semítico.

194 En el DRAE no es mencionada.

195 En el DRAE no se encuentra.

196 En el DRAE no es mencionada.

197 En el DRAE: lengua acadia.
} 
Asirio-babilonio, Ling. m. Lengua semítica oriental de Mesopotamia: su variante babilonia es del II milenio a. C. y en el I llega hasta el año 600 a. C.; el asirio se habló en la parte alta del valle del Éufrates, el babilonio en la baja. Usan la escritura cuneiforme ${ }^{198}$.

Cananeo, Ling. m. Antigua lengua semítica occidental testimoniada en breves inscripciones cuneiformes en Palestina y el Sinaí en el II milenio a. C. ${ }^{199}$.

Fenicio, Ling. m. Variedad del Cananeo usada en el I milenio a. C. en las ciudades costeras de Tiro y Sidón, usó el alfabeto descubierto por primera vez en Ugarit ${ }^{200}$.

Púnico, Ling. m. Variedad del fenicio escrita en Cartago y sus colonias desde el siglo VIII a. C. ${ }^{201}$.

Arameo, Ling. m. Variedad del semítico occidental hablada en Siria, Asiria, Israel y Trasjordania desde el siglo IX a. C. Fue lengua administrativa del Imperio aqueménida. Quedan todavía en Siria y Turquía algunos enclaves en que se habla ${ }^{202}$.

Nabateo, Ling. m. Variante del arameo usada en Petra desde el siglo IV a. C. al I d. C. ${ }^{203}$.

Palmireno, Ling. Variante del arameo usada en Palmira en el siglo I d. C..$^{204}$.

Siriaco, Ling. Variante del arameo usada en Edesa desde el siglo I a. C., fue importante lengua de cultura en Siria desde el siglo II d. C. ${ }^{205}$.

Hebreo, Ling. m. Lengua semítica occidental relacionada con el arameo y escrita en Israel desde el año 600 a. C. La ha usado toda la cultura hebrea, hasta que su uso quedó reducido principalmente al religioso. El moderno estado hebreo lo ha estandarizado para el uso normal. Tiene unos 8 millones de hablantes. Se escribe en un alfabeto que solo marca las consonantes ${ }^{206}$.

Árabe, Ling. m. Lengua semítica occidental, testimoniada en la época preislámica (entre los nabateos, de donde viene su alfabeto o alifato), luego en la preclásica, sucediéndole la variante clásica a partir de Mahoma. Hoy el árabe clásico se usa principalmente en el culto, hay diversas variantes habladas. Su uso ha sido extendido por los árabes por gran parte del mundo. Tiene unos 150 millones de hablantes. Se escribe en un alfabeto que solo marca las consonantes ${ }^{207}$.

Maltés, Ling. m. Lengua hablada en Malta, fundada en el árabe. Hablado por cerca de medio millón de personas ${ }^{208}$.

\footnotetext{
198 En el DRAE no figura.

199 En el DRAE no hay acepción lingüística.

${ }^{200}$ En el DRAE: antigua lengua semítica hablada por los fenicios.

201 En el DRAE no hay acepción lingüística.

202 Cf. DRAE Arameo 4.

${ }^{203}$ En el DRAE, no hay acepción lingüística.

204 En el DRAE no figura.

205 En el DRAE, la lengua hablada por los antiguos siriacos.

206 En el DRAE, definición muy pobre: la lengua semítica hablada en Israel.

207 En el DRAE: definición pobre.

208 En el $D R A E$, no hay acepción lingüística.
} 
Tigre, Ling. m. Lengua árabe hablada en Eritrea ${ }^{209}$.

Tigriña, Ling. m. Lengua árabe hablada en Etiopía por unos 5 millones de personas $^{210}$.

Amárico, Ling. m. Lengua semítica árabe hablada en Etiopía. Es lengua nacional, cuenta con unos 15 millones de hablantes ${ }^{211}$.

Fulaní o Fula, Ling. m. Lengua africana hablada en Nigeria, Senegal, Burkina Faso y territorios contiguos por unos 6 millones de personas ${ }^{212}$.

Suahili, Ling. m. Conjunto de lenguas bantú habladas en Tanzania, Zanzíbar y Kenia por unos 30 millones de personas ${ }^{213}$.

Bantú, Ling. m. Familia de lenguas africanas habladas en el Congo, Sudán, Uganda, Tanzania, etcétera ${ }^{214}$.

Bubi, Ling. m. Lengua bantú, hablada en Gabón y en la isla de Fernando Póo (hoy Bioko) $)^{215}$.

Fan, Ling. m. Lengua bantú, hablada en Gabón y en Guinea Ecuatorial ${ }^{216}$.

Kikuyu, Ling. m. Lengua bantú hablada en Kenia por unos 5 millones de personas $^{217}$.

Herero, Ling. m. Lengua africana hablada en Namibia por escasa población ${ }^{218}$.

Grebo, Ling. m. Familia de lenguas africanas habladas en Gabón, Liberia y Costa de Marfil ${ }^{219}$.

Ibo, Ling. m. Lengua africana hablada en Nigeria por unos 15 millones de personas $^{220}$.

Yoruba, Ling. m. Lengua africana hablada en Nigeria por unos 15 millones de personas ${ }^{221}$.

${ }^{209}$ En el DRAE no figura.

210 En el DRAE no figura.

211 En el DRAE no figura.

212 En el DRAE no figura.

213 Retoco swahili en DRAE.

214 Sí en el DRAE, lo retoco.

215 En el DRAE no se menciona.

${ }^{216}$ En el DRAE no se menciona.

217 En el DRAE no es mencionado.

218 En el DRAE no figura.

${ }^{219}$ En el DRAE no figura.

${ }^{220}$ En el DRAE no figura.

221 En el DRAE no figura. 
Mon-Camboyana, Ling. f. Familia de lenguas habladas en Malasia, Tailandia, Camboya, Vietnam, Laos, Birmania y China ${ }^{222}$.

Vietnamita, Ling. m. Lengua de la familia mon-camboyana, hablada en Vietnam. Es hablado por unos 50 millones de personas ${ }^{223}$.

Munda, Ling. m. Familia de lenguas habladas en la India (Madhya Pradesh, Orissa, Bengala, etcétera) ${ }^{224}$.

Jemer o Camboyano, Ling. m. Lengua nacional de Camboya, también hablada en Vietnam y Tailandia. La hablan unos 6 millones de personas ${ }^{225}$.

Mon, Ling. m. Lengua hablada en Birmania y Tailandia ${ }^{226}$.

Tai, Ling., m. Lengua hablada en Tailandia por unos 45 millones de perso$\operatorname{nas}^{227}$.

Sino-Tibetana, Ling. f. Gran familia lingüística escindida en la sínica y la tibeto-birmana ${ }^{228}$.

Tibeto-Birmana, Ling. f. Familia de lenguas dependiente de la sino-birma$\mathrm{na}^{229}$.

Chino, Ling. m. La gran lengua de China, dentro de la familia sino-tibetana. Existen muchas variedades de chino, entre ellas el chino mandarín, con casi mil millones de hablantes ${ }^{230}$.

Cantonés, Ling. m., Dialecto chino hablado por unos 60 millones de personas en Cantón ${ }^{231}$.

Hunanés, Ling. m. Dialecto chino hablado en Hunán por unos 30 millones de personas ${ }^{232}$.

Quejiá, Ling. m. Dialecto chino del Sur hablado por unos 28 millones de personas $^{233}$.

Chuan, Ling. m. Dialecto del tai hablado en China (Guangxi) por 12 millones de personas ${ }^{234}$.

\footnotetext{
${ }^{222}$ En el DRAE no figuran.

${ }^{223}$ En el DRAE: lengua vietnamita.

${ }^{224}$ En el DRAE no figura.

${ }^{225}$ En el DRAE no figura.

${ }^{226}$ En el DRAE no figura.

${ }^{227}$ En el DRAE no figura.

${ }^{228}$ En el DRAE no figura.

${ }^{229}$ En el DRAE no figura.

${ }^{230}$ DRAE: idioma de los chinos.

231 No figura en el DRAE.

${ }^{232}$ En el DRAE no figura.

${ }^{233}$ No figura en el DRAE.

${ }^{234}$ En el DRAE no figura.
} 
Lao, Ling. m. Dialecto del tai que es la lengua nacional de Laos. Es hablado por unos tres millones de personas ${ }^{235}$.

Butanés, Ling. m. Lengua del Bután, de la familia tibeto-birmana ${ }^{236}$.

Tibetano, Ling. m. Familia formada por numerosas lenguas que se hablan en el Tíbet, Nepal, China, Pakistán e India. Son unos dos millones de hablantes ${ }^{237}$.

Serpa, Ling. m. Lengua del Nepal, de la familia tibetana ${ }^{238}$.

Birmano, Ling. m. Lengua de la familia tibeto-birmana, hablada en Birmania por unos 30 millones de personas ${ }^{239}$.

\subsection{Lenguas amerindias}

Amerindias, Ling. f. plu. Se denomina así a las lenguas indígenas de América. Algunas están extintas, otras siguen hablándose ${ }^{240}$.

Inui, Ling., m. Lengua esquimal de Canadá, hablada por unas 70.000 personas $^{241}$.

Apache, Ling. m. Grupo de lenguas amerindias, habladas en Nuevo México, Arizona, la Colombia británica y Alaska. El nombre inglés procede del español ${ }^{242}$.

Navajo, Ling. m. Lengua del grupo apache, hablada en Arizona. El nombre procede del español ${ }^{243}$.

Algonquina, Ling. f. Familia de lenguas amerindias habladas en Canadá, zona de Quebec, y en Estados Unidos, zona de los Grandes Lagos.

Mohicano, Ling. m. Lengua de la familia algonquina, hoy extinta, que se hablaba con otras en la zona de Nueva York ${ }^{244}$.

235 En el DRAE no figura.

236 No figura en el DRAE.

${ }^{237}$ DRAE: lengua de los tibetanos.

${ }^{238}$ En el DRAE no figura.

${ }^{239}$ En el DRAE, no figura como lengua.

${ }^{240}$ En el DRAE no aparece con sentido lingüístico.

241 No aparece en el DRAE.

${ }^{242}$ No aparece en el DRAE.

${ }^{243}$ No recogida en el DRAE.

${ }^{244}$ No recogida en el DRAE. 
Hopi, Ling. m. Lengua amerindia del grupo yuko-azteca hablada por una comunidad reducida en Oklahoma ${ }^{245}$.

Comanche, Ling. m. Lengua amerindia del grupo yuko-azteca, hablada por una comunidad reducida en Oklahoma ${ }^{246}$.

Iroquesa, Ling. f. Familia de lenguas amerindias habladas en Canadá y en Estados Unidos (Oklahoma, Estado de Nueva York). Varias están extin$\operatorname{tas}^{247}$.

Séneca, Ling. m. Subfamilia de lenguas amerindias en Ontario, Canadá ${ }^{248}$.

Hurón, Ling. m. Grupo de lenguas amerindias extintas o casi extintas en Ontario (Canadá) y Oklahoma ${ }^{249}$.

Cheroquí, Ling. m., Lengua de la familia iroquesa, hablada en Oklahoma y Carolina del Norte ${ }^{250}$.

Mohaqués, Ling. m., Lengua de la familia iroquesa hablada en Quebec y Ontario meridional (Canadá) ${ }^{251}$.

Chontal, Ling. m. Lengua amerindia hablada en la región de Oaxaca (México) $)^{252}$.

Quiché, Ling. m. Lengua maya hablada en Guatemala por más de 700.000 personas $^{253}$.

Mixteco, Ling. m. Lengua amerindia hablada en Oaxaca (México), por unas 750.000 personas. Da nombre a una familia de lenguas. El nombre proviene del nahua y significa «habitante de las nubes» ${ }^{254}$.

Chichimeca, Ling. m. Lengua amerindia hablada hoy por una comunidad reducida en Guanajuato (México). El nombre proviene del nahua. Significa «perro, bárbaro» ${ }^{255}$.

Otomí, Ling. m. Lengua amerindia hablada en Veracruz, Hidalgo, Puebla, Tlascala por unas 250.000 personas $^{256}$.

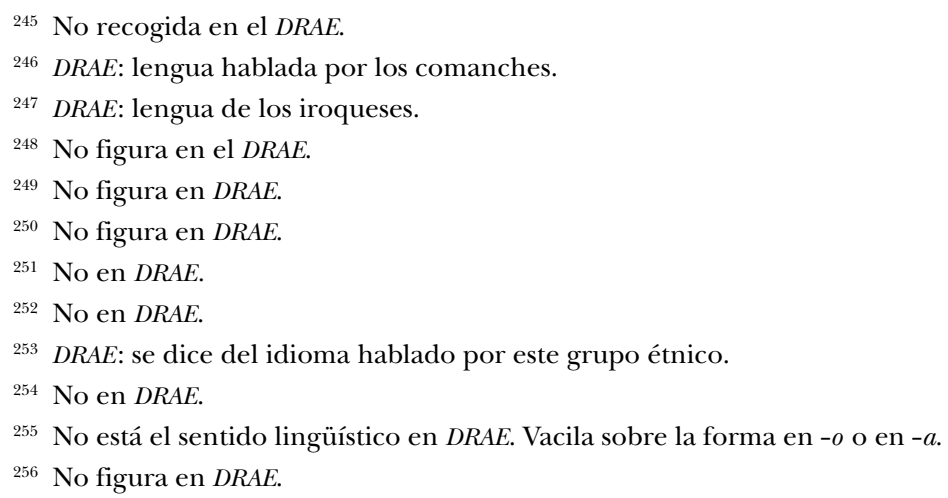


Zapoteca, Ling. m. Lengua amerindia hablada en Oaxaca por unas 200.000 personas $^{257}$.

Yuto-Azteca, Ling. m. Gran familia de lenguas amerindias que van del hopi al nahua ${ }^{258}$.

Nahua, Ling. m., La lengua del imperio Azteca, perteneciente al grupo yukoazteca, venido del Norte, de Arizona y Nuevo México. El nahua clásico era la lengua de aquel imperio, tras él los misioneros españoles contribuyeron a su difusión. Sus variantes modernas las hablan hoy más de millón y medio de personas. Desarrolló en época clásica una escritura pictográfica ${ }^{259}$.

Maya, Ling. m. Conjunto de lenguas del pueblo maya, que desarrolló una gran cultura a partir del año 2000 a. C., en Guatemala. Siguen hablándose en Yucatán, Guatemala, Bélice y Honduras. Desarrollaron una escritura a partir de los llamados glifos ${ }^{260}$.

Glifos, Ling. m. plu. Signos mínimos de la escritura maya, que se combinan entre sí y parece que contienen determinantes varios ${ }^{261}$.

Huasteco, Ling. m. Lengua maya en la costa atlántica de México, al N. de Veracruz ${ }^{262}$.

Yucateco, Ling. m. Lengua maya hablada en Yucatán por en torno a medio millón de personas ${ }^{263}$.

Lacandón, Ling. m. Lengua maya hablada en Yucatán ${ }^{264}$.

Totonaca, Ling. m. Lengua amerindia hablada en Puebla y Veracruz, en México $^{265}$.

Mataco, Ling. m. Lengua amerindia hablada en Argentina (Salta) y Paraguay $^{266}$.

Caribe, Ling. m. Familia de lenguas amerindias habladas en Colombia, Guayana, Surinam, Venezuela, Brasil ${ }^{267}$.

${ }^{257}$ No figura en el DRAE.

${ }^{258}$ Sí en $D R A E$, pero no hay acepción lingüística.

${ }^{259}$ DRAE: «se dice de la lengua hablada principalmente por los indios mexicanos». Hay también en DRAE un artículo náhuatl.

${ }^{260}$ En DRAE, Maya 2.: familia de lenguas habladas por los mayas.

${ }^{261}$ No en el DRAE.

${ }^{262}$ DRAE: lengua hablada por los huastecos.

${ }^{263}$ No hay acepción lingüístico en el DRAE.

${ }^{264}$ DRAE: lengua de la familia maya hablada por los lacandones.

${ }^{265}$ DRAE: Totonaca 3. Lengua del mismo (pueblo).

${ }_{266}$ DRAE: lengua hablada por los matacos.

${ }^{267}$ DRAE: lengua de los caribes, dividida en numerosos dialectos. 
Arahuaco, Ling. m. Familia de lenguas amerindias habladas en Colombia, Brasil, Perú, Bolivia ${ }^{268}$.

Tupí, Ling. m. Familia de lenguas habladas en Brasil y emparentadas con el guarani $^{269}$.

Guaraní, Ling. m. Grupo de lenguas habladas sobre todo en Paraguay, pero también en Argentina, Bolivia y Brasil. Es lengua nacional, con el español, en Paraguay, donde lo hablan más de 4 millones de personas ${ }^{270}$.

Jíbaro, Ling. m. Familia de lenguas habladas en Ecuador y Perú, algunas en peligro de extinción ${ }^{271}$.

Yanomami, Ling. m. Familia de lenguas amerindias en Venezuela y Brasil, algunas en peligro de extinción ${ }^{272}$.

Quechua, Ling. m. Familia de lenguas en el Perú y Ecuador. Son habladas por unos 7 millones de personas. Proceden, parece, de la región de Huari, en la costa, del siglo vi d. C., y su difusión se debe al imperio Inca, primero, y a la acción de los misioneros españoles, después ${ }^{273}$.

Aimara, Ling. m. Lengua hablada en Bolivia por unos dos millones de personas, sobre todo en la región de Tihuanaco y el lago Titicaca, pero también en el Perú y Chile. Parece proceder de la cultura Nazca, en la costa (siglos IV-III/II a. C.) y tener relación de origen con el quechua. Lo hablan unas 600.000 personas $^{274}$.

Araucano, Ling. m. Antigua lengua amerindia de Chile, cuyos hablantes se enfrentaron a Valdivia y los conquistadores españoles. De ella descienden el mapuche y el huilliche actuales ${ }^{275}$.

Huilliche, Ling. m. Lengua amerindia de Chile, hablada desde Valdivia a la zona de Chiloé por algunos miles de personas ${ }^{276}$.

Mapuche, Ling. m. Lengua amerindia de Chile, descendente del araucano y hablada hoy por unas quinientas mil personas. El nombre viene de mapudongo «habla del país» 277 .

\footnotetext{
268 Retoco el DRAE.

269 En el DRAE hay tupí como lengua, también tupíguaran.

270 Retoco el DRAE.

271 DRAE: lengua hablada por los jíbaros.

${ }^{272}$ DRAE: lengua hablada por los yanomami.

273 Retoco la definición del DRAE.

${ }^{274}$ En el DRAE: lengua aimara.

275 En el DRAE no hay acepción lingüística.

276 No hay acepción lingüística en el DRAE.

277 En el DRAE: lengua de los mapuches.
} 


\subsection{Lenguas malayo-polinesias y otras del Pacífico}

Malayo-Polinesio, Ling. m. Gran familia lingüística de Malasia y Polinesia, cuyas lenguas se extienden a través de muchos miles de kilómetros. Fue reconocida como tal por Hervás y Panduro ${ }^{278}$.

Austronesio, Ling. m. Vasta familia de familias de lenguas que se divide en el grupo formosano y el malayo-polinesio. Su origen está seguramente en las islas del SE. asiático ${ }^{279}$.

Formosano, Ling. m. Grupo de lenguas habladas en Formosa, que está emparentado con el malayo-polinesio, constituyendo ambos el llamado austronesio $^{280}$.

Rapa-Nui, Ling. m. También pascuense, lengua de la isla de Pascua, de la familia malayo-polinesia ${ }^{281}$.

Pascuense, Ling. m. También rapa-nui, lengua de la isla de Pascua, de la familia malayo-polinesia ${ }^{282}$.

Hawayano, Ling. m. Lengua de las islas Hawai, de la familia malayo-polinesia $^{283}$.

Chamorro, Ling. m. Lengua malayo-polinesia de la isla de Guam, tiene unos 50.000 hablantes ${ }^{284}$.

Tagalo, Ling. m. Lengua filipina, malayo-polinesia, hablada sobre todo en Luzón por unos 17 millones de personas ${ }^{285}$.

Bisayo, Ling. m. Familia de lenguas filipinas, de la familia malayo-polinesia, en las islas bisayas, en Filipinas ${ }^{286}$.

Malgache, Ling. m. Lengua de Madagascar, de la familia malayo-polinesia. Tiene unos 14 millones de hablantes ${ }^{287}$.

Fiyiano, Ling. m. Lengua de las islas Fiyi, de la familia malayo-polinesia ${ }^{288}$.

\footnotetext{
278 Retoco el DRAE.

${ }^{279}$ No aparece en el DRAE.

280 No aparece en el DRAE.

281 No aparece en el DRAE.

${ }^{282}$ No hay acepción lingüística en el DRAE.

${ }^{283}$ En el DRAE, prácticamente igual.

${ }^{284}$ El DRAE habla de los chamorros, no de su lengua.

${ }^{285}$ DRAE: lengua que hablan los tagalos.

286 DRAE: lengua bisaya.

287 Retoco el DRAE.

288 Sin acepción lingüística en el DRAE.
} 
Tahitiano, Ling. m. Lengua de la isla de Tahití en la Polinesia francesa, de la familia malayo-polinesia. Lo hablan unas 50.000 personas ${ }^{289}$.

Rapa, Ling. m. Lengua hablada en la Polinesia francesa. Es de la familia malayo-polinesia ${ }^{290}$.

Maorí, Ling. m. Lengua hablada en Nueva Zelanda, de la familia malayopolinesia. Lo hablan unas 100.000 personas $^{291}$.

Javanés, Ling. m. Lengua con varios dialectos hablada en Java, Indonesia y Bali. Pertenece a la familia malayo-polinesia. Es conocido desde el siglo IX d. C. y tiene una literatura desde el siglo XV. Tiene unos 50 millones de hablantes.

Balinés, Ling. m. Lengua hablada en Bali, Java e Indonesia. Pertenece a la familia malayo-polinesia ${ }^{292}$.

Sundanés, Ling. m. Lengua malayo-polinesia hablada en Indonesia, Java y Bali, por unos 15 millones de personas ${ }^{293}$.

Toba, Ling. m. Lengua malayo-polinesia hablada en Sumatra por unos $2 \mathrm{mi}-$ llones de personas ${ }^{294}$.

Samoano, Ling. m. Lengua malayo-polinesia hablada en Samoa. Lo hablan unas 300.000 personas $^{295}$.

Malayo, Ling. m. Lengua que, en diversos dialectos, es hablado en la Península de Malaca, Borneo, Sumatra, las Molucas, etc., por unos 15 millones de personas ${ }^{296}$.

Indonesio, Ling. m. Bajo este nombre se recogen diversas lenguas de Sumatra y de otras islas indonesias. Pertenece a la familia malayo-polinesia. Lo hablan unos 22 millones de personas ${ }^{297 .}$

Papúes, Ling. m. Lenguas de un grupo del malayo-polinesio centrado en Nueva Guinea y hablado también en Java e islas de Indonesia ${ }^{298}$.

Andamanés, Ling. m. Grupo de lenguas habladas en las islas Andamán y emparentado con las papúes ${ }^{299}$.

\footnotetext{
289 Sin acepción lingüística en el DRAE.

290 No figura en el DRAE.

291 DRAE: lengua hablada en ciertas zonas de Nueva Zelanda.

292 No figura en el DRAE.

293 No figura en el DRAE.

294 No figura en el DRAE.

295 DRAE: perteneciente o relativo a esta lengua.

296 DRAE: lengua malaya.

${ }^{297}$ DRAE: perteneciente o relativo a estas lenguas.

298 Sin acepción lingüística en el $D R A E$.

299 No figura en el DRAE.
} 
Australianas, Ling. f. plu. Se llama así al conjunto de las lenguas de Australia, que se consideran de origen común, pero se proponen para él fechas muy diferentes (la más reciente, el 4000 a. C.) ${ }^{300}$.

Pama-ñunga, Ling. f. La familia más conocida de lenguas australianas ${ }^{301}$.

Tasmanio, Ling. m. Lengua extinta de Tasmania ${ }^{302}$.

\section{REFERENCIAS BIBLIOGRÁFICAS}

Adrados, F. R. (2006): «Observaciones a definiciones de lenguas, dialectos, etc. en el DRAE», en Corcillum. Estudios de traducción, lingüistica y filología dedicados a Valentín García Yebra, Madrid, Arco/Libros, pp. 963-969.

Moreno Cabrera, J. C. (1990): Lenguas del mundo, Madrid, Visor.

- (2003): El Universo de las lenguas, Madrid, Castalia.

300 No hay acepción lingüística en el DRAE.

301 No figura en el DRAE.

${ }^{302}$ No figura en el DRAE. 
